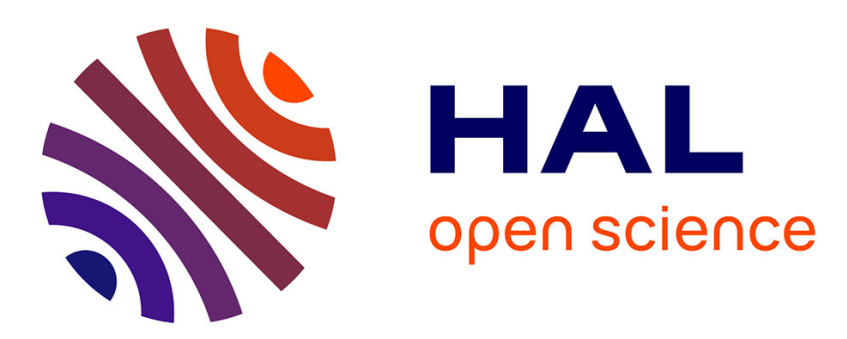

\title{
The Syntrophy hypothesis for the origin of eukaryotes revisited
}

Purificación López-García, David Moreira

\section{To cite this version:}

Purificación López-García, David Moreira. The Syntrophy hypothesis for the origin of eukaryotes revisited. Nature Microbiology, 2020, 5 (5), pp.655-667. 10.1038/s41564-020-0710-4 . hal-02988531

\section{HAL Id: hal-02988531 \\ https://hal.science/hal-02988531}

Submitted on 3 Dec 2020

HAL is a multi-disciplinary open access archive for the deposit and dissemination of scientific research documents, whether they are published or not. The documents may come from teaching and research institutions in France or abroad, or from public or private research centers.
L'archive ouverte pluridisciplinaire HAL, est destinée au dépôt et à la diffusion de documents scientifiques de niveau recherche, publiés ou non, émanant des établissements d'enseignement et de recherche français ou étrangers, des laboratoires publics ou privés. 
1

2 Perspectives

3

4

5

6 The Syntrophy hypothesis for the origin of eukaryotes revisited 7

8 Purificación López-García ${ }^{1}$ and David Moreira ${ }^{1}$

9

10

11

12

13

14

15

16

17

18

19

${ }^{1}$ Ecologie Systématique Evolution, CNRS, Université Paris-Saclay, AgroParisTech, Orsay, France

*Correspondence to: puri.lopez@u-psud.fr

(5)

17

9


The discovery of Asgard archaea, phylogenetically closer to eukaryotes than other archaea, together with improved knowledge of microbial ecology impose new constraints on emerging models for the origin of the eukaryotic cell (eukaryogenesis). Long-held views are metamorphosing in favor of symbiogenetic models based on metabolic interactions between archaea and bacteria. These include the classical Searcy's and hydrogen hypothesis, and the more recent Reverse Flow and Entangle-Engulf-Enslave $\left(E^{3}\right)$ models. Two decades ago, we put forward the Syntrophy hypothesis for the origin of eukaryotes based on a tripartite metabolic symbiosis involving a methanogenic archaeon (future nucleus), a fermentative myxobacterial-like deltaproteobacterium (future eukaryotic cytoplasm) and a metabolically versatile methanotrophic alphaproteobacterium (future mitochondrion). A refined version later proposed the evolution of the endomembrane and nuclear membrane system by invagination of the deltaproteobacterial membrane. Here, we adapt the Syntrophy hypothesis to contemporary knowledge, shifting from the original hydrogen and methane-transfer-based symbiosis (HM-Syntrophy) to a tripartite hydrogen and sulfur-transfer-based model (HS-Syntrophy). We propose a sensible ecological scenario for eukaryogenesis in which eukaryotes originated in early Proterozoic microbial mats from the endosymbiosis of a hydrogen-producing Asgard archaeon within a complex sulfate-reducing deltaproteobacterium. Mitochondria evolved from versatile, facultatively aerobic, sulfide-oxidizing and, potentially, anoxygenic photosynthesizing, alphaproteobacterial endosymbionts that recycled sulfur in the consortium. The HS-Syntrophy hypothesis accounts for (endo)membrane, nucleus and metabolic evolution in a realistic ecological context. We compare and contrast the HS-Syntrophy hypothesis to other models of eukaryogenesis, notably in terms of the mode and tempo of eukaryotic trait evolution, and discuss several model predictions and how these can be tested. 
Eukaryogenesis was a unique major evolutionary transition resulting in significant average cell complexity increase. This foundational event led to an impressive radiation of morphologically diverse phyla, most of them unicellular (protists) but many including multicellular taxa such as animals, fungi, kelp and land plants ${ }^{1}$. Elusive for a long time, reconstructing a mechanistically plausible and ecologically realistic model for the origin of eukaryotes appears now within reach thanks to recent advances in molecular phylogenomic tools, genome-binning from metagenomes and a better knowledge of microbial diversity and function in natural ecosystems. Until recently, notwithstanding the generally accepted endosymbiotic origin of mitochondria and chloroplasts, models proposing the symbiotic origin of eukaryotes directly from bacterial and archaeal ancestors were largely dismissed ${ }^{2,3}$. The prevailing view stated that an independent proto-eukaryotic lineage sister to archaea evolved most eukaryotic features (complex cytoskeleton, endomembranes, nucleus, phagocytosis, etc.) before it engulfed the mitochondrial alphaproteobacterial ancestor ${ }^{4-6}$. This view started to vacillate with the realization that truly primary amitochondriate eukaryotes were not known ${ }^{7}$ and additionally deteriorated with phylogenomic trees where eukaryotes branched within archaea, albeit without clear sister groups ${ }^{8}$. The discovery of Asgard archaea, a phylogenetically deep-branching lineage sharing more and more similar genes with eukaryotes than other archaea ${ }^{9,10}$, has further fostered this paradigm shift on eukaryogenesis. Eukaryotes are no longer on the same footing as archaea and bacteria as one of the original primary domains of life ${ }^{11}$; they are a third, but secondary, domain resulting from the evolutionary merging of specific archaeal and bacterial linages ${ }^{2,6,12-14}$. Moreover, current knowledge about Asgard general metabolic potential and preferred biotopes (mostly sediments and microbial mats, where intimate metabolic interactions are the rule $^{3,15}$ ), realistically favor symbiogenetic models based on metabolic symbioses or syntrophies ${ }^{16,17}$. This is further supported by the syntrophic nature of the first cultured Asgard member, Candidatus Prometheoarchaeum syntrophicum, an anaerobic organism able to grow in symbiosis with a sulfatereducing deltaproteobacterium, a methanogenic archaeon or both ${ }^{18}$. Collectively, this strongly supports cooperative models for the origin of the eukaryotic cell ${ }^{2,3,6,17}$ whereby higher complexity evolved from the physical integration of prokaryotic cells combined with extensive gene and genome shuffling ${ }^{12,19-21}$.

The first symbiogenetic models date back to more than 20 years ago. Among them, the more detailed were the Serial Endosymbiosis Theory ${ }^{22-24}$, the Hydrogen hypothesis ${ }^{25}$ and the Syntrophy hypothesis ${ }^{26,27}$. In the original Syntrophy hypothesis, we proposed that eukaryotes evolved from a tripartite metabolic symbiosis based on i) interspecies hydrogen transfer from a fermenting deltaproteobacterial host to an endosymbiotic methanogenic archaeon and ii) methane recycling by a versatile methanotrophic, facultative aerobic alphaproteobacterium ${ }^{26}$ (Hydrogen-Methane $-\mathrm{HM}$ - Syntrophy). From an ecological perspective, these metabolic interactions were reasonable, being widespread in anoxic and redoxtransition settings ${ }^{2}$. However, knowledge about archaeal diversity and metabolism was then much more fragmentary than today, and the metabolic potential of uncultured lineages remained inaccessible. The probable involvement of an Asgard archaeal relative in eukaryogenesis imposes new constraints, such that realistic models need to take into account their metabolic potential and ecology. Accordingly, several symbiogenetic models are currently being put forward. They differ on the metabolic interactions proposed (Box 1) and, importantly, the tempo and mode of evolution of key eukaryotic traits (Box 2). Here, we present an updated version of the Syntrophy hypothesis based on a tripartite metabolic

81 symbiosis involving interspecific hydrogen and sulfur-transfer (HS-Syntrophy) occurring in redox82 transition ecosystems: a complex sulfate-reducing deltaproteobacterium (host), an endosymbiotic 
hydrogen-producing Asgard-like archaeon (future nucleus) and a metabolically versatile, facultatively aerobic, sulfide-oxidizing and potentially anoxygenic photosynthesizing, alphaproteobacterium (future mitochondrion). We briefly discuss the evolution of the endomembrane system, the nucleus and the genome $^{19}$ in the framework of the HS-Syntrophy hypothesis. This model makes several predictions that differentiate it from alternative scenarios including, notably, the two-step origin of the nucleus (first, as distinct metabolic compartment before its consecration as major genetic reservoir and expression center) and the bacterial origin of eukaryotic membranes and cytoplasm. We propose ways to specifically test some aspects of different eukaryogenesis models and offer suggestions for future avenues of research.

91

\section{The ecological context of the eukaryogenetic symbiosis}

Despite the challenges associated to the interpretation of the earliest life traces, the oldest reliable eukaryotic fossils can be dated back to at least $1.65 \mathrm{Ga}^{28}$. This imposes a minimal age for the origin of eukaryotes that roughly agrees with the oldest boundaries of recent molecular dating estimates for the last eukaryotic common ancestor (LECA; 1.0-1.6 Ga) ${ }^{29}$ and the eukaryotic radiation $(<1.84 \mathrm{Ga})^{30}$. At the same time, LECA was complex, being endowed with mitochondria and resembling modern protists ${ }^{20,21}$. Although the alphaproteobacterial lineage that gave rise to the mitochondrion remains to be precisely identified $^{31}$, it is clear that the mitochondrial ancestor was aerobic ${ }^{32}$, but likely also possessed anaerobic respiratory capacities (as in many modern protists). This implies that i) aerobic respiration had already evolved in bacteria when the mitochondrial endosymbiosis occurred and ii) oxic or microaerophilic conditions existed in the environment where the mitochondrial endosymbiosis took place or in its immediate vicinity. Aerobic respiration possibly evolved (almost) in parallel to cyanobacterial oxygenic photosynthesis, which led to the oxygenation of the atmosphere, the Great Oxidation Event (GOE), some 2.4 Ga ago at the beginning of the Proterozoic (2.5-0.5 Ga) ${ }^{33,34}$. Therefore, eukaryogenesis took place between the GOE and the minimum age of the oldest unambiguous eukaryotic fossils ${ }^{28}$. If some older, more difficult to affiliate, fossils ${ }^{35}$ are indeed eukaryotic, eukaryogenesis might have occurred during the first three to five hundred million years after the GOE.

What did the Earth look like at that time? Before the GOE, the atmosphere and oceans were essentially anoxic, which constrained existing biogeochemical cycles. The atmosphere rapidly oxygenated from $2.33 \mathrm{Ga}$ but sulfate levels in oceans increased slower ${ }^{33}$, limiting the biological S cycle ${ }^{36,37}$. This means that oceans were oxygen-poor during the early Proterozic, when eukaryotes evolved; the deep ocean remained anoxic until the beginning of the Phanerozoic $(500 \mathrm{Ma})^{38-40}$. If an aerobic mitochondrial ancestor suggests oxygen availability at or near the environment where eukaryotes finally evolved, current knowledge on Asgard archaea ecology and metabolism strongly suggests that the archaeon involved in eukaryogenesis, and hence the first eukaryogenetic steps, were strictly anaerobic. Asgard archaea are mostly found in deep-sea sediments ${ }^{9,10,18,41}$ and microbial mats ${ }^{10}$, including thermophilic ones $^{10,42}$. Thus, with the exception of some derived planktonic Heimdallarchaeota, which more recently acquired the capacity to oxidize organics using nitrate or oxygen as terminal electron acceptors ${ }^{16,43}$, the vast majority of Asgard archaea thrive in anoxic environments, as their ancestors did, degrading organics and producing or consuming hydrogen ${ }^{16}$. These observations argue in favor of redox transition environments, where anoxic and oxic/microoxic zones are in close proximity, as favored ecosystems for eukaryotes evolved in shallow sediments or microbial mats, where redox gradients established, like 


\section{Eukaryogenetic syntrophies}

162 Considering this historical and ecological context, we favor the idea that eukaryogenesis occurred in 163 microbial mats (or similarly stratified shallow sediments) with marked redox gradients (Fig. 1a),

164 potentially mildly warm. Oxygenic photosynthesis (and in close proximity, aerobic respiration) might have 165 first evolved in warm environments. Indeed, most deep-branching cyanobacteria are thermophilic ${ }^{65,66}$. 166 Although universal molecular mechanisms to cope with reactive oxygen species exist ${ }^{67,68}$ and might have 167 been co-opted from antioxidant-prone compounds very early ${ }^{69,70}$, oxygen toxicity would have been

today, from the oxygen-enriched surface where cyanobacterial oxygenic photosynthesis took place to the increasingly anoxic layers below.

Phototrophic microbial mats are particularly interesting potential eukaryogenesis cradles. They were the Proterozoic 'forests', dominating shallow aquatic and terrestrial habitats, as abundant fossil stromatolites (lithified microbial mats) show ${ }^{34,44,45}$. These light- and redox-stratified microbial communities are phylogenetically and metabolically diverse ${ }^{42,46,47}$. Although microorganisms in modern mats are different from their Proterozoic counterparts, core metabolic functions have been mostly preserved across phyla ${ }^{48}$ and at the ecosystem level, suggesting that functional shifts observed in mats across redox gradients today reflect early metabolic transitions ${ }^{49}$. Most primary production occurs in upper layers, where light can penetrate, via photosynthetic carbon fixation. The upper cyanobacterial oxygenic-photosynthesis layer is typically followed by a reddish layer dominated by oxygen-tolerant anoxygenic photosynthesizers (Alpha- and Gammaproteobacteria) and often an underlying green layer of photosynthetic Chloroflexi and/or Chlorobi. Organic matter fixed in the upper mat layers is progressively degraded in deeper, anoxic layers, by extremely diverse microbial communities ${ }^{42,50,51}$. Two broad zones can be distinguished in vertical anoxic profiles where, respectively, sulfate reduction and methanogenesis dominate $^{46}$ (Fig. 1a). Here, like in anoxic sediments, the degradation of organic matter involves syntrophy ${ }^{52}$, mostly implicating interspecies hydrogen (or, directly, electron ${ }^{53}$ ) transfer. In anoxic environments, pairs of electron donors and acceptors display low redox potential differences such that many energy-generating metabolic reactions can only proceed in the presence of syntrophic sinks ${ }^{54}$. Methanogenic archaea and sulfate-reducing bacteria (SRB) belonging to the Deltaproteobacteria are frequently engaged in syntrophy. Deltaproteobacteria are metabolically diverse and can use or produce hydrogen or, directly, electrons ${ }^{55}$, being frequently involved in interspecies hydrogen or electron transfer $^{53}$. Many of them oxidize organic compounds with sulfate, but they can also be autotrophic ${ }^{56}$ (including in syntrophy ${ }^{57}$ ), use other electron donors and acceptors (including metals, such as arsenic ${ }^{58}$ ), ferment or switch between metabolisms depending on the environmental conditions ${ }^{59}$. Deltaproteobacteria establish widespread syntrophies with archaea; with methanogens when acting as hydrogen producers, with methanotrophic archaea when acting as hydrogen-consuming sulfatereducers ${ }^{60}$. Mutualistic interactions between methanogens and deltaproteobacteria can be rapidly selected, leading to specialized syntrophy ${ }^{61,62}$. Deltaproteobacterial SRB also establish symbioses with sulfide-oxidizing or other bacteria and eukaryotes ${ }^{2,59,63}$. In addition to methanogens and SRB, a wide variety of uncultured lineages occurs in anoxic sediment and microbial mat layers, where archaea thrive. Many of these archaea seem to be involved in cycling organics, particularly alkanes, being likely engaged in syntrophies with hydrogen-scavengers ${ }^{49,52,64}$. Indeed, the first cultured Asgard archaeon can grow by degrading amino acids in syntrophy with either a sulfate-reducing deltaproteobacterium and/or a methanogen ${ }^{18}$. 
advantageously relieved in thermophilic mats by its rapid release into the atmosphere (oxygen is poorly soluble at high temperature). The original (HM) Syntrophy hypothesis postulated, on solid microbial ecology grounds, the evolution of eukaryotes from well-known widespread symbioses between fermenting (hydrogen-producing), ancestrally SRB, deltaproteobacteria and methanogenic archaea. SRB and methanogens, which compete for hydrogen, can readily evolve stable syntrophy in co-culture ${ }^{61,62}$. We additionally favored a myxobacterial-like deltaproteobacterium due to the similarities shared by these complex social bacteria and eukaryotes ${ }^{19,26}$. This symbiosis would have established at the sulfate-methane transition zone but evolved upwards in the redox gradient, where an additional symbiosis formed with a versatile methanotrophic alphaproteobacterium that scavenged the methane released by the primary consortium. We cannot completely reject such tripartite metabolic symbiosis at the origin of eukaryotes since methanogenesis, originally thought exclusive of Euryarchaeota, occurs across archaeal phyla and might have been ancestral to the archaeal domain ${ }^{71-74}$. However, although methanogenesis might be eventually discovered in Asgard archaea (some Asgard archaea do have methyl-coenzyme $\mathrm{M}$ reductases probably involved in the reverse, anaerobic alkane oxidation, reaction ${ }^{41}$ ), current genomic comparisons seem to exclude it from their ancestral metabolic capacities ${ }^{16}$.

In this context, we now favor a similar eukaryogenetic process but based on alternative, albeit equally ecologically relevant, metabolic symbioses (Fig. 1). In our HS-Syntrophy hypothesis, we propose that eukaryotes evolved from the syntrophic interaction of a sulfate-reducing (hydrogen/electronrequiring) deltaproteobacterium, possibly sharing some complex traits with myxobacteria, and a hydrogen-producing Asgard-like archaeon. This deltaproteobacterium may have been metabolically versatile or mixotrophic, but in symbiosis with the archaeon, it respired sulfate. This initial facultative symbiosis was stabilized by the incorporation of the archaeon as endosymbiont (Fig. 1b-c). This consortium likely established first in deeper anoxic layers and subsequently migrated upwards in the redox gradient, where it established a second (initially facultative) symbiosis with a sulfide-oxidizing alphaproteobacterium that acted as both, sulfide sink and sulfate donor for the Asgarddeltaproteobacterium consortium (Fig. 1b-c). Alternatively, the two facultative symbioses might have coexisted although, in this case, we favor a later obligatory endosymbiosis of the alphaproteobacterial ancestor $^{19}$. This would be in line with genomic evidence suggesting a late mitochondrial symbiosis ${ }^{75}$. Given the dominance of $\mathrm{H}_{2} \mathrm{~S}$-dependent anoxygenic photosynthesizing bacteria in microbial mats and their interaction with SRB for sulfur cycling in upper layers ${ }^{76,77}$, the versatile, facultatively aerobic mitochondrial ancestor was likely also photosynthetic (or mixotrophic). Interestingly, the possibility that mitochondrial cristae evolved from intracytoplasmic membranes typical of photosynthetic Alphaproteobacteria has been highlighted ${ }^{78}$. This tripartite symbiotic consortium became definitely stabilized when the alphaproteobacterium became an endosymbiont within the deltaproteobacterium (Fig. 1d). In our view, the first eukaryotic common ancestor (FECA) is neither an archaeon nor a bacterium, but the first obligatory symbiogenetic consortium. Strictly speaking, this would correspond to the integrated symbiosis of the three partners that contributed to the final making of the eukaryotic cell and genome. But the FECA stage could also be decoupled in time in two subsequent stages corresponding to the integration of the Asgard archaeon within the deltaproteobacterium (FECA 1) and the acquisition of the mitochondrial endosymbiont (FECA 2).

In our model, up to the FECA stage, the eukaryogenetic syntrophies were based on the same metabolic exchange that occurred in the corresponding facultative symbioses (hydrogen between the 
archaeon and the SRB; sulfide/sulfate between the SRB and SOB). However, the incorporation of the mitochondrial ancestor as obligatory endosymbiont implied a radical change in the metabolism of the whole consortium, constraining the outcome of the eukaryogenetic process. Because the mitochondrial ancestor was also aerobic and could get a much higher energy yield by directly oxidizing organics, the consortium started to rely solely on aerobic respiration (Fig. 1e). This resulted in the loss of the lessefficient anaerobic archaeal metabolism and bacterial sulfate-reduction. At the same time, the protoeukaryote migrated to the fully oxic layers of the mats, spreading on oxic surfaces and, upon the development of motility mechanisms, colonizing the planktonic realm. Cellular changes that included the development of an extensive endomembrane system (see below) led to the LECA stage (Fig. 1f).

The HS-Syntrophy model implies three prokaryotic partners that became integral part of the future eukaryotic cell. However, other pre-eukaryogenetic symbioses might have occurred at the facultative syntrophy stage, eventually leaving historical traces in the form of transferred genes to the eukaryogenetic symbiotic partners. One traditional criticism to symbiogenetic models proposing the endosymbiosis of one prokaryote within another prokaryote is the absence of phagocytosis in prokaryotes $^{2,4,6,79,80}$. Mainstream models now accept a symbiogenetic origin of eukaryotes but only under the premise that an endomembrane system, a developed cytoskeleton and phagocytosis evolved in the archaeal ancestor prior to the engulfment of the mitochondrial ancestor ${ }^{6,81}$. However, prokaryotes harboring endosymbiotic prokaryotes are known and might be more frequent than currently thought. In addition to the well-known cases of gammaproteobacterial symbionts within betaproteobacterial endosymbionts in mealybugs ${ }^{82}$ and rickettsiales in tick mitochondria ${ }^{83}$, old electron microscopy studies ${ }^{84-}$ ${ }^{86}$ and more recent observations ${ }^{87}$ suggest the potential occurrence of prokaryotic endosymbionts in bacteria. Interestingly, a recent report of prey engulfment by planctomycetes ${ }^{88}$ suggests that bona fide bacterial phagocytosis exists, albeit based on different molecular grounds than eukaryotic phagocytosis ${ }^{88}$. In the case of archaea, although Nanoarchaeota can be associated to the inter-membrane space in the archaeon Ignicoccus hospitalis $^{89}$, true endosymbionts remain to be observed. Consequently, regardless the mechanism, these collective observations suggest that prokaryotic endosymbioses, at least within bacteria, are feasible.

\section{Membranes and endomembranes}

The eukaryotic plasma membrane and endomembrane system, including the endoplasmic reticulum (ER), the nuclear membrane, the Golgi apparatus and other vesicular components (vacuoles, lysosomes, etc.) are interconnected (are either continuous or can fuse and merge). They share a similar composition, with typical bacterial-like phospholipids ${ }^{2,90}$. The phospholipid bilayer in eukaryotes is particularly flexible and can undergo deformation, bending, fusion and fission. This is achieved thanks to a highly developed cytoskeleton $^{91}$, coating components (e.g. clathrin/AP1-5, COPI, TSET, COPII, retromer, ESCRT complexes), ARF/ARF-like GTPases and their regulators, and fusion machinery (involving SNARE complex, multisubunit tethering complexes, Rab GTPases and regulatory factors) ${ }^{92-94}$. Both, the cytoskeleton and membrane remodeling and fusion complexes were already present in LECA, which was capable of phagocytosis, secretion and trafficking, and have a chimeric origin ${ }^{20,93,95-97}$. In addition to innovations ${ }^{21,95}$, some cytoskeletal and membrane-remodeling proteins are archaeal-like (e.g. actin, profilin, ESCRT proteins ${ }^{6,98}$, perhaps some GTPases ${ }^{99}$, although some of these might be bacterial ${ }^{100,101}$ ) but a significant number of 
endomembrane system-related proteins could also be of bacterial, though not alphaproteobacterial, origin $^{75}$. The biosynthesis of sterols is notably of bacterial origin ${ }^{102}$.

Most eukaryogenetic models propose a two-partner symbiosis in which the archaeal host incorporated the alphaproteobacterial ancestor of mitochondria. This implies a shift of the host membrane from the more rigid archaeal, glycerol-1-phosphate (G1P)-based ether-linked isoprenoid phospholipids to the more flexible and permeable bacterial glycerol-3-phosphate (G3P)-based, usually ester-linked, fatty acid phospholipids ${ }^{2,90}$ (Box 2). However, such a transition with, in particular, a G1P-toG3P-based phospholipid shift, has never been observed in nature (some thermophilic bacteria use etherlinks, long-term-known exceptions ${ }^{90}$ ). Recently, an engineered Escherichia coli strain was forced to express archaeal phospholipids, making up to $30 \%$ of the total membrane phospholipids ${ }^{103}$. The engineered heterochiral-membrane strain was viable and, interestingly, the expressed archaeal lipids recruited G1P, suggesting that stereospecificity is somehow linked to the phospholipid composition, in a peculiar form of membrane heredity. However, if more than $30 \%$ archaeal lipids incorporated to the membrane, severe growth impairment was observed and the shape of cells became aberrant; they produced numerous vesicles and underwent asymmetric cell division ${ }^{103}$. One could therefore ask how the expression of archaeal phospholipids affects $E$. coli fitness and whether such engineered strain would be able to survive competition with normal bacteria in natural environments. Archaeal and bacterial phospholipids impose very different local physicochemical conditions that constrain integral membrane proteins ${ }^{104}$. As a consequence, a membrane lipid composition shift implies an extensive adaptation of the whole membrane-associated proteome ${ }^{105}$. In this context, neither the stability of heterochiral liposomes ${ }^{106}$ nor the (partial) expression of archaeal phospholipids in engineered E. coli ${ }^{103}$ can be taken as evidence for an archaeal-to-bacterial membrane transition. While the bacterial nature of eukaryotic phospholipids represents a serious difficulty for models invoking an archaeal host, it is naturally explained by the bacterial nature of the host in the Syntrophy hypothesis (Box 2, Fig. 1).

In the HS-Syntrophy model, the endomembrane system results from the invagination of the deltaproteobacterium inner membrane and the internalization of the periplasm. The outer bacterial plasma membrane would be retained as the eukaryotic plasma membrane. Many bacteria harbor endomembrane compartments linked to specialized biochemical functions ${ }^{107}$. These include the wellknown cyanobacterial thylakoids, but also compartments in magnetotactic bacteria ${ }^{108}$, anammox bacteria $^{109}$ and Poribacteria ${ }^{110}$. Some Planctomycetes develop a thoroughly studied nuclear-like compartment ${ }^{111}$ and a similar structure has been recently described in the candidate phylum Atribacteria ${ }^{112}$. This implies that the internalization of membranes is relatively common across bacterial phyla. Although Deltaproteobacteria with endomembranes have not been described, their diversity is far from fully explored and they have membrane-remodeling potential. For instance, developed cytoskeletons (a prerequisite for extensive membrane remodeling) exist in the predatory Bdellovibrio ${ }^{113}$ but also in myxobacteria, which are able to generate protruding membrane tubes that interconnect cells ${ }^{114}$. In the HS-Syntrophy model, similarly to the former HM-Syntrophy ${ }^{19}$, the initial driving force for endomembrane evolution is the establishment of a secretory system that connected the endosymbiotic archaeon with the periplasm (Fig. 1c-d). As in contemporary heterotrophic deltaproteobacteria, the periplasm was the digestive space of the host deltaproteobacterium in which complex organics uptaken

291 from the environment were hydrolyzed to simpler organics. Some of these simpler organics (e.g. amino acids, short hydrocarbons) were used by the archaeon for its organoheterotrophic metabolism, which 
yielded hydrogen used in turn by the SRB host. By being an endosymbiont, the archaeon maximized its uptake surface for small organics from the bacterial cytoplasm. In turn, the deltaproteobacterial host maintained an optimal uptake surface for complex organics from the environment while having a ready internal source of hydrogen (or electrons) for sulfate reduction. As the symbiosis evolved, many genes were transferred from the deltaproteobacterium to the archaeon, which progressively centralized genes and gene expression for the whole consortium. This included, notably, many hydrolytic enzymes required for the periplasmic degradation of complex organics. These enzymes were transported from the archaeal compartment towards the original bacterial periplasm via an incipient endomembrane system that, eventually, fully surrounded the archaeon and constituted the future nuclear membrane (see below). This implied the evolution of a transport system only through the archaeal membrane since, on the bacterial side, transporters for the export of newly synthesized hydrolytic enzymes to the periplasm and the environment already existed. Bacterial transporters might have initially been inserted also in the archaeal membranes (following gene transfer to the archaeal genome) but later replaced by channels communicating with bacteria-derived pore-like structures and allowing the export of increasingly bigger and varied substrates (see below). The transfer of hydrolytic enzymes to the digestive periplasmic space via the endomembrane system was essential to prevent the hydrolysis of cytoplasmic components (Fig. 1d). At the same time, in this way, the digestive space largely increased. Hence, the initial digestive and trafficking-related endomembrane system was the precursor of the nuclear membrane and the ER but also of the different eukaryotic vesicles related to digestive processes (lysosomes, peroxisomes, digestive vacuoles). Upon the endosymbiosis of the mitochondrial ancestor and the loss of the archaeal and SRB metabolism, the organics were directly oxidized via aerobic respiration by the alphaproteobacterium and the endomembrane system was retained for the trafficking of proteins synthesized in the proto-nucleus (Fig. 1e) and, with time, in association with the ER itself (Fig. 1f). At the same time, the ancient periplasm was completely internalized and the former digestive periphery transferred to independent vesicular compartments (Fig. 1f). The secretory Golgi apparatus as well as other endocytotic and exocytotic systems developed in parallel. The association of archaeal membrane-bending systems (e.g. ESCRT) with the host bacterial membranes facilitated the process of endomembrane formation.

\section{The origin of the nucleus}

Most eukaryogenetic models fail to advance convincing selective forces to explain why the nucleus evolved $^{2}$. We propose, like in the HM-Syntrophy ${ }^{19}$, a two-step process entailing two sequential selective forces. First, a proto-nucleus evolved as a different metabolic compartment. This chimeric compartment was composed of the endosymbiotic archaeon and the surrounding proto-nuclear membrane of deltaproteobacterial origin (Fig. 1c-d). The first selective force for the evolution of the nuclear membrane was the need to export bacterial enzymes already synthesized by the archaeon (after their genes were transferred to the archaeal genome) to the periplasmic space. Its first role was therefore secretory (export towards the trafficking endomembrane system). Other proteins of archaeal origin also started to be exported, contributing to the evolution of several chimeric eukaryotic systems. Once the archaeal genome started to host essential genes from its symbiotic partners, and these genes were lost from the donor genomes, the archaeon started to centralize protein synthesis for the whole consortium. This entailed the development of a transport mechanism from the archaeal cytoplasm to the bacterial 
endomembrane system, which was at the origin of the nuclear pore. This implied the formation of coordinated apertures through the archaeal membrane and the proto-nuclear membrane, although these apertures might have formed only on the bacterial membrane (future nuclear pores) with archaeal membrane transporters facilitating export prior to archaeal membrane loss. The potential to establish communicating pores exists in both, archaea and deltaproteobacteria. Archaea are able to establish intercellular cytoplasmic bridges and fuse ${ }^{115}$. Myxobacterial deltaproteobacteria are also able to fuse their membranes ${ }^{116,117}$ and develop contact-dependent abilities, including coordinated gliding via junctional pore complexes ${ }^{118-121}$. Progressively, ribosomes concentrated around these incipient communicating pores, eventually migrating to the host's cytoplasm along the endomembrane system (future ER), where protein synthesis started to take place. This led to a progressive decoupling of translation, which became associated to the ER, and transcription, which took place in the archaeal cytoplasm (future nucleoplasm).

As the consortium evolved between FECA and LECA, after the mitochondrial ancestor was fixed in the consortium and the archaeal and SRB metabolisms were lost in favor of the more efficient mitochondrial respiration, the archaeal membrane became useless and was completely lost (membrane loss is not infrequent in the framework of endosymbiosis ${ }^{122}$ ). However, during this evolutionary process, extensive genome evolution took place ${ }^{19}$. This involved (endo)symbiotic gene transfer (EGT) to the archaeal genome, likely accompanied by other HGT, which was largely facilitated by active processes fostering genome evolution, such as gene and genome fragment duplication and reshuffling. As transcription and translation decoupled, introns invaded the future eukaryotic genome. They likely derived from the original self-splicing introns of the alphaproteobacterial endosymbiont ${ }^{123}$, possibly complemented by other mechanisms ${ }^{124,125}$. Once introns invaded the genome, the proto-nuclear membrane was selectively retained (exapted) to maintain the transcription-translation uncoupling. Therefore, preventing the deleterious massive synthesis of aberrant proteins was the second selective force acting during nuclear evolution ${ }^{19}$. Intron invasion has been proposed as exclusive selective force for the origin of the nucleus ${ }^{126}$. However, in our view, transcription-translation uncoupling, and therefore a nuclear membrane, must preexist in order for introns to spread and not the opposite ${ }^{2}$. Not only the insertion of one or a few introns in essential genes would be immediately deleterious, but the evolution of a continuous nuclear membrane requires intermediate steps during which transcription and translation are still coupled that intron invasion as selective force cannot explain.

The initial chimeric proto-nuclear pore evolved into the modern nuclear pore as traffic check-point and hub of gene regulation ${ }^{127}$. We view the nucleolus and the ribosomal particle assembly process as remnants of the archaeal origin of the nuclear compartment ${ }^{19}$. The assembly of eukaryotic ribosomes is a complex and energy-costly process that takes place in the nucleolus. Ribosomal proteins are synthesized in the cytoplasm and transported to the nucleus. After assembly with rRNA in the nucleolus, ribosomal particles are transported back to the cytoplasm, where they associate to the ER for function ${ }^{128}$. The set of proteins involved (processome) is essentially of archaeal origin ${ }^{129}$.

\section{The make-up of a composite genome}

372 During eukaryogenesis, various mechanisms shaped the evolving eukaryotic genome. These included 373 HGT, EGT, gene duplication, loss and new gene creation, accompanied by the invasion of introns and 374 mobile selfish elements. The directionality of gene transfer to the archaeal genome and its establishment 375 as future nuclear genome might have been simply dictated by chance; as the consequence of an essential 
gene transfer from one genome to the other genome followed by loss in the donor ${ }^{19}$. The retention of the archaeal endosymbiont genome as future nuclear genome is often criticized on the ground that in extant cases of endosymbioses, endosymbionts tend to reduce their genomes in favor of the host's. However, known extant endosymbioses occur within eukaryotes, which are already composite cells harboring mitochondria and eventually chloroplasts for which many essential genes already reside in the nuclear genome. Therefore, the eukaryotic nuclear genome is essential and must centralize genes coming from any new incoming endosymbiont. The situation was radically different at the origin of eukaryotes when organelle reliance on the nuclear genome was not yet established and symbiotic partners were mutually dependent. In the Syntrophy hypothesis, the archaeal genome became the future nuclear genome. Bacterial components were thus included in an archaeal genomic background, leading to the long-term recognized mixed heritage of eukaryotic genomes, with 'informational' genes (related to DNA replication, transcription and translation) being archaeal-like, and 'operational' genes (involved in energy and carbon metabolism) bacterial-like ${ }^{130}$. While true in general terms, a closer look to the bacterial-like genes in eukaryotes poses some questions.

Most symbiogenetic models invoke only two partners, an archaeal host and the alphaproteobacterial ancestor of mitochondria (Box 1). Consequently, two predictions follow: i) host (archaeal-like) genes must dominate over the endosymbiont (alphaproteobacterial-like) genes and ii) most bacterial-like eukaryotic genes must be of alphaproteobacterial origin. However, neither of them holds. Bacterial-like genes are more abundant than archaeal-like genes in eukaryotic genomes ${ }^{131}$ and genes with alphaproteobacterial ancestry only represent a minority of bacterial-like genes in modern eukaryotes ${ }^{75,132}$ and LECA ${ }^{133}$. To explain this 'silent' non-alphaproteobacterial bacterial majority in eukaryotic genomes, the progressive erosion of ancient phylogenetic signal making it difficult to pinpoint the precise origin of those genes and massive HGT from diverse bacterial donors to the archaeal and/or the alphaproteobacterial symbiotic partners have been invoked ${ }^{131,134}$. High bacteria-to-archaea HGT levels have been observed in several phyla ${ }^{135}$, including the Asgard archaea ${ }^{9,10}$. However, the patterns observed in eukaryotic genomes could be only explained if genes transferred to the archaeal and/or alphaproteobacterial ancestors of eukaryotes had been subsequently lost in all their sister lineages, which is unlikely ${ }^{133}$. In addition, eukaryotic alphaproteobacterial-like genes have significantly shorter branches than other bacterial-like genes in phylogenetic trees including prokaryotic homologues ${ }^{75}$. This suggests a late mitochondrial arrival in a host with an already chimeric genome ${ }^{75}$. Moreover, if alphaproteobacterial-like genes mostly relate to mitochondrial functions, bacterial genes of non-alphaproteobacterial ancestry seem to be involved in other essential eukaryotic traits such as the endomembrane system, reinforcing the idea that they evolved prior to the mitochondrion ${ }^{75}$. Non-alphaproteobacterial genes appear to derive from various bacterial phyla (with Deltaproteobacteria and Actinobacteria among the most frequent donors), suggesting successive ancient waves of HGT from these phyla and/or the implication of several bacterial symbionts during eukaryogenesis (Box 2e). Symbiogenetic models involving more than two partners are often dismissed applying a simplistic parsimony argument. However, parsimony is not evolutionary evidence and, in most complex ecosystems, multiple symbioses are widespread ${ }^{3}$. The first cultured Asgard archaeon can indeed grow in symbiosis with one sulfate-reducing deltaproteobacterium and one methanogenic archaeon ${ }^{18}$. If we transpose a similar symbiosis at the onset of eukaryogenesis, a significant number of deltaproteobacterial-like genes in eukaryotes might be explained by HGT during the long-term coexistence with a symbiont that later disappeared without integrating the consortium ${ }^{18}$. Additional 
bacterial ecto- or endo-symbionts might have also transferred genes, leading to the mosaic origin of eukaryotic bacterial-like genes as proposed in the 'pre-mitochondrial symbiosis' model ${ }^{133}$ and on the line of the 'shopping-bag model' proposed for the evolution of plastid genomes ${ }^{136}$.

However, the presence of many non-alphaproteobacterial bacterial-like genes in eukaryotes is compatible with the HS-syntrophy model. Accordingly, deltaproteobacterial genes would have been acquired by EGT. Interestingly, deltaproteobacterial-like genes seem to be the most abundant nonalphaproteobacterial category, and also older ${ }^{75}$. Inferring the precise phylogenetic origin of genes of different ages in eukaryotic genomes is far from trivial due to mutational saturation and the erosion of phylogenetic signal in increasingly older genes ${ }^{137}$. Furthermore, each potential additional symbiont could contribute a number of genes acquired by HGT from different donors in such a way that the apparent number of eukaryogenetic symbiotic partners would appear inflated. Nonetheless, strong phylogenetic signal supports the deltaproteobacterial origin of many eukaryotic genes involved in diverse functions and structures. In addition to early identified deltaproteobacterial-like eukaryotic genes ${ }^{26}$, the list also includes antimicrobial defensins ${ }^{138}$, Ser/Thr/Tyr protein kinases ${ }^{139}$, PPP protein phosphatases ${ }^{140}$, high mobility group A proteins ${ }^{141}$, isoprenoid biosynthesis enzymes ${ }^{142}$, cyclitol synthases ${ }^{143}$ and some kinetochore proteins ${ }^{97}$. Mitochondria also recruited some deltaproteobacterial proteins, potentially reflecting an alpha-delta-proteobacterial symbiosis, such as thiolases ${ }^{144}$, fatty acid beta-oxidation enzymes $^{145}$, and possibly, some proteins involved in anaerobic metabolism. Stemming from the versatility of many alphaproteobacteria, we view the mitochondrial ancestor as a facultative aerobe able to carry out anaerobic respiration with various electron acceptors but also substrate-level phosphorylation ${ }^{27}$. Several genes involved in these reactions seem ancestral in eukaryotes, branching close to deltaproteobacteria and other anaerobic bacteria ${ }^{146}$. Although they are usually interpreted as independent HGT acquisitions from various donors ${ }^{146}$, these observations can alternatively support a deltaproteobacterial anaerobic respiration toolkit in ancestral eukaryotic mitochondria, subsequently lost to different degrees in aerobic lineages.

\section{Future prospects}

Any model on eukaryogenesis must account for the evolution of key eukaryotic traits (e.g. genome complexity, nature and origin of eukaryotic membranes/endomembranes and the nucleus), in a way that i) is mechanistically plausible and ii) explains the observed patterns and the causes (selective forces) for the evolution of those traits in iii) a realistic ecological context. In this framework, our HS-Syntrophy model takes into account constraints imposed by the discovery of Asgard archaea and their ancestral metabolic potential to put forward one of the most comprehensive eukaryogenetic models. This model presents some difficulties, notably in the centralization of the genome and protein synthesis by the archaeon with subsequent export to the deltaproteobacterial host. However, it is ecologically relevant, fits well with the observed chimerism of eukaryotic genomes and has the advantage, over archaeal hostbased models (Box 1), of readily explaining the bacterial-like nature of eukaryotic membranes ${ }^{2,90}$. The HSSyntrophy hypothesis makes several predictions that differentiate it from other hypotheses (Table 1). Some of these are shared with the HM-Syntrophy model and include the presence of EGT-derived deltaproteobacterial genes in eukaryotes that should be mostly involved in membrane, cell-signaling and cytoplasmic functions. Others, such as the involvement of a potentially photosynthetic S-oxidizing 
alphaproteobacterium, specifically characterize the HS-Syntrophy. These predictions suggest that such specific Alpha- and Deltaproteobacterial lineages, phylogenetically closer to eukaryotes than other bacterial lineages, might exist. The nature of the alphaproteobacterial ancestor of mitochondria is indeed still $_{\text {cryptic }}{ }^{31}$. If such lineages were discovered through environmental studies in microbial mats or sediments, the HS-Syntrophy would gain support. These Syntrophy models are realistically based on wellknown metabolic interactions in microbial mats or sediments, but metabolic variants involving a similar tripartite symbiosis and eukaryogenetic process might be also envisaged within a more general Syntrophy model; its distinctive features being the nuclear origin from an archaeal endosymbiont in a bacterial cytoplasm and the independent acquisition of the mitochondrial ancestor.

Beyond the Syntrophy hypothesis, progress in several areas is needed to answer open questions and differentiate major model types (Table 1). In archaeal host-based symbiotic models ${ }^{16,18,147,148}$, three major issues need attention. First, the archaeal-to-bacterial membrane transition remains a major drawback. Cases of membrane transitions implying complete phospholipid-type replacement and concomitant membrane proteome adaptation are not observed in nature. If bacteria and, more particularly archaea, can be engineered to i) accomplish the full replacement of membrane phospholipids for the opposite type and ii) be competitive in real environmental conditions (permissive fitness cost), the historical feasibility of such transition would be supported. So far, the evidence is lacking. In some models, the emission of cell protrusions and a progressive engulfment of an alphaproteobacterium is preferred over immediate phagocytosis ${ }^{18,147}$. That long process would favor phospholipid exchange and replacement of the rigid archaeal phospholipids for more flexible bacterial ones ${ }^{147}$. However, it is unclear how such a "slow phagocytosis" process would occur across prokaryotic generations, which are needed for evolution to take place (phospholipid replacement and proteome adaptation) prior to true engulfment. Second, two-partner models need to propose convincing detailed evolutionary mechanisms and selective forces for the origin of the eukaryotic nucleus, which are so far lacking. Finally, eukaryogenetic models need to explain the 'silent bacterial majority' in eukaryotic genomes. In two-partner models, HGT from different bacteria to any of the partners might be the most logical explanation, but this does not necessarily explain why groups of functionally-related genes seem to come from a few bacterial groups ${ }^{75,133}$, even if some HGT and phylogenetic reconstruction noise are likely involved in these observations. In-depth phylogenomic analyses including a broad taxon sampling and, if identified, the closest bacterial and archaeal relatives of eukaryotes will be needed. Collectively, the information gathered from environmental, experimental cell biology and phylogenomic studies should help to discriminate existing models, refine them or create new ones. More than ever, solving the eukaryogenesis riddle seems at hand.

4951 Adl, S. M. et al. The revised classification of eukaryotes. J Eukaryot Microbio/ 59, 429-493 (2012).

4962 Lopez-Garcia, P. \& Moreira, D. Open questions on the origin of eukaryotes. Trends Ecol Evol 30, 697-

$497 \quad 708$ (2015).

4983 Lopez-Garcia, P., Eme, L. \& Moreira, D. Symbiosis in eukaryotic evolution. J Theor Biol 434, 20-33 $499 \quad$ (2017). 
4 Poole, A. M. \& Penny, D. Evaluating hypotheses for the origin of eukaryotes. Bioessays 29, 74-84 (2007).

5 de Duve, C. The origin of eukaryotes: a reappraisal. Nat Rev Genet 8, 395-403 (2007).

6 Eme, L., Spang, A., Lombard, J., Stairs, C. W. \& Ettema, T. J. G. Archaea and the origin of eukaryotes. Nat Rev Microbiol 15, 711-723 (2017).

7 Embley, T. M. \& Hirt, R. P. Early branching eukaryotes? Curr. Opin. Genet. Dev. 8, 624-629 (1998).

8 Cox, C. J., Foster, P. G., Hirt, R. P., Harris, S. R. \& Embley, T. M. The archaebacterial origin of eukaryotes. Proc Natl Acad Sci U S A 105, 20356-20361 (2008).

9 Spang, A. et al. Complex archaea that bridge the gap between prokaryotes and eukaryotes. Nature 521, 173-179 (2015).

10 Zaremba-Niedzwiedzka, K. et al. Asgard archaea illuminate the origin of eukaryotic cellular complexity. Nature 541, 353-358 (2017).

11 Williams, T. A., Cox, C. J., Foster, P. G., Szöllősi, G. J. \& Embley, T. M. Phylogenomics provides robust support for a two-domains tree of life. Nat Ecol Evol, 138-147 (2019).

12 Mclnerney, J. O., O'Connell, M. J. \& Pisani, D. The hybrid nature of the Eukaryota and a consilient view of life on Earth. Nat Rev Microbiol 12, 449-455 (2014).

13 Koonin, E. V. Archaeal ancestors of eukaryotes: not so elusive any more. BMC Biol 13, 84 (2015).

14 Williams, T. A. \& Embley, T. M. Changing ideas about eukaryotic origins. Philos Trans R Soc Lond B Biol Sci 370, 20140318 (2015).

15 Libby, E., Hebert-Dufresne, L., Hosseini, S. R. \& Wagner, A. Syntrophy emerges spontaneously in complex metabolic systems. PLoS Comput Biol 15, e1007169 (2019).

16 Spang, A. et al. Proposal of the reverse flow model for the origin of the eukaryotic cell based on comparative analyses of Asgard archaeal metabolism. Nat Microbiol (2019).

17 Lopez-Garcia, P. \& Moreira, D. Eukaryogenesis, a syntrophy affair. Nat Microbiol 4, 1068-1070 (2019).

18 Imachi, H. et al. Isolation of an archaeon at the prokaryote-eukaryote interface. bioRxiv, 726976 (2019).

19 López-García, P. \& Moreira, D. Selective forces for the origin of the eukaryotic nucleus. Bioessays 28, 525-533 (2006).

20 Koonin, E. V. \& Yutin, N. The dispersed archaeal eukaryome and the complex archaeal ancestor of eukaryotes. Cold Spring Harb Perspect Biol 6, a016188 (2014).

21 Koonin, E. V. Origin of eukaryotes from within archaea, archaeal eukaryome and bursts of gene gain: eukaryogenesis just made easier? Philos Trans R Soc Lond B Biol Sci 370, 20140333 (2015).

22 Sagan, L. On the origin of mitosing cells. J Theor Biol 14, 255-274 (1967).

23 Margulis, L. Origin of eukaryotic cells. (Yale University Press, 1970).

24 Margulis, L., Dolan, M. F. \& Guerrero, R. The chimeric eukaryote: origin of the nucleus from the karyomastigont in amitochondriate protists. Proc Natl Acad Sci U S A 97, 6954-6959 (2000).

25 Martin, W. \& Muller, M. The hydrogen hypothesis for the first eukaryote. Nature 392, 37-41 (1998).

26 Moreira, D. \& López-García, P. Symbiosis between methanogenic archaea and delta-Proteobacteria as the origin of eukaryotes: The syntrophic hypothesis. J. Mol. Evol. 47, 517-530 (1998).

27 López-García, P. \& Moreira, D. Metabolic symbiosis at the origin of eukaryotes. Trends Biochem Sci 24, 88-93 (1999).

28 Javaux, E. J. Challenges in evidencing the earliest traces of life. Nature 572, 451-460 (2019).

29 Eme, L., Sharpe, S. C., Brown, M. W. \& Roger, A. J. On the age of eukaryotes: evaluating evidence from fossils and molecular clocks. Cold Spring Harb Perspect Biol 6, a016139 (2014).

30 Betts, H. C. et al. Integrated genomic and fossil evidence illuminates life's early evolution and eukaryote origin. Nat Ecol Evol 2, 1556-1562 (2018). 
31 Martijn, J., Vosseberg, J., Guy, L., Offre, P. \& Ettema, T. J. G. Deep mitochondrial origin outside the sampled alphaproteobacteria. Nature 557, 101-105 (2018).

32 Roger, A. J., Munoz-Gomez, S. A. \& Kamikawa, R. The Origin and Diversification of Mitochondria. Curr Biol 27, R1177-r1192 (2017).

33 Luo, G. et al. Rapid oxygenation of Earth's atmosphere 2.33 billion years ago. Sci Adv 2, e1600134 (2016).

34 Knoll, A. H., Bergmann, K. D. \& Strauss, J. V. Life: the first two billion years. Philos Trans R Soc Lond B Biol Sci 371 (2016).

35 El Albani, A. et al. Organism motility in an oxygenated shallow-marine environment 2.1 billion years ago. Proc Natl Acad Sci U S A 116, 3431-3436 (2019).

36 Canfield, D. E., Habicht, K. S. \& Thamdrup, B. The Archean sulfur cycle and the early history of atmospheric oxygen. Science 288, 658-661 (2000).

37 Halevy, I., Johnston, D. T. \& Schrag, D. P. Explaining the structure of the Archean mass-independent sulfur isotope record. Science 329, 204-207 (2010).

38 Shen, Y., Knoll, A. H. \& Walter, M. R. Evidence for low sulphate and anoxia in a mid-Proterozoic marine basin. Nature 423, 632-635. (2003).

39 Poulton, S. W., Fralick, P. W. \& Canfield, D. E. The transition to a sulphidic ocean approximately 1.84 billion years ago. Nature 431, 173-177 (2004).

40 Stolper, D. A. \& Keller, C. B. A record of deep-ocean dissolved O2 from the oxidation state of iron in submarine basalts. Nature 553, 323 (2018).

41 Seitz, K. W. et al. Asgard archaea capable of anaerobic hydrocarbon cycling. Nat Commun 10, 18221822 (2019).

42 Saghaï, A. et al. Unveiling microbial interactions in stratified mat communities from a warm saline shallow pond. Environ Microbiol 19, 2405-2421 (2017).

43 Bulzu, P. A. et al. Casting light on Asgardarchaeota metabolism in a sunlit microoxic niche. Nat Microbiol (2019).

44 Hamilton, T. L., Bryant, D. A. \& Macalady, J. L. The role of biology in planetary evolution: cyanobacterial primary production in low-oxygen Proterozoic oceans. Environ Microbiol 18, 325-340 (2016).

45 Lenton, T. M. \& Daines, S. J. Matworld - the biogeochemical effects of early life on land. New Phytol 215, 531-537 (2017).

46 Bolhuis, H., Cretoiu, M. S. \& Stal, L. J. Molecular ecology of microbial mats. FEMS Microbiol Ecol 90, 335-350 (2014).

47 Paerl, H. W., Pinckney, J. L. \& Steppe, T. F. Cyanobacterial-bacterial mat consortia: examining the functional unit of microbial survival and growth in extreme environments. Environ Microbio/ 2, 11-26 (2000).

48 Martiny, J. B., Jones, S. E., Lennon, J. T. \& Martiny, A. C. Microbiomes in light of traits: A phylogenetic perspective. Science 350, aac9323 (2015).

49 Gutierrez-Preciado, A. et al. Functional shifts in microbial mats recapitulate early Earth metabolic transitions. Nat Ecol Evol 2, 1700-1708 (2018).

50 Harris, J. K. et al. Phylogenetic stratigraphy in the Guerrero Negro hypersaline microbial mat. ISME J 7, 50-60 (2013).

51 Wong, H. L., Smith, D. L., Visscher, P. T. \& Burns, B. P. Niche differentiation of bacterial communities at a millimeter scale in Shark Bay microbial mats. Sci Rep 5, 15607 (2015).

52 Dombrowski, N., Seitz, K. W., Teske, A. P. \& Baker, B. J. Genomic insights into potential interdependencies in microbial hydrocarbon and nutrient cycling in hydrothermal sediments. Microbiome 5, 106 (2017). 
53 Lovley, D. R. Syntrophy Goes Electric: Direct Interspecies Electron Transfer. Annu Rev Microbiol 71, 643-664 (2017).

54 Fenchel, T. \& Finlay, B. J. Ecology and evolution in anoxic worlds. (Oxford University Press, 1995).

55 Lovley, D. R. Happy together: microbial communities that hook up to swap electrons. ISME J (2016).

56 Mall, A. et al. Reversibility of citrate synthase allows autotrophic growth of a thermophilic bacterium. Science 359, 563-567 (2018).

57 Krukenberg, V. et al. Candidatus Desulfofervidus auxilii, a hydrogenotrophic sulfate-reducing bacterium involved in the thermophilic anaerobic oxidation of methane. Environ Microbio/ 18, 30733091 (2016).

58 Oremland, R. S. \& Stolz, J. F. The ecology of arsenic. Science 300, 939-944. (2003).

59 Muyzer, G. \& Stams, A. J. The ecology and biotechnology of sulphate-reducing bacteria. Nat Rev Microbiol 6, 441-454 (2008).

60 Knittel, K. \& Boetius, A. Anaerobic oxidation of methane: progress with an unknown process. Annu Rev Microbiol 63, 311-334 (2009).

61 Hillesland, K. L. et al. Erosion of functional independence early in the evolution of a microbial mutualism. Proc Natl Acad Sci U S A 111, 14822-14827 (2014).

62 Hillesland, K. L. \& Stahl, D. A. Rapid evolution of stability and productivity at the origin of a microbial mutualism. Proc Natl Acad Sci U S A 107, 2124-2129 (2010).

63 Monteil, C. L. et al. Ectosymbiotic bacteria at the origin of magnetoreception in a marine protist. Nat Microbiol 4, 1088-1095 (2019).

64 Wang, Y., Wegener, G., Hou, J., Wang, F. \& Xiao, X. Expanding anaerobic alkane metabolism in the domain of Archaea. Nat Microbiol 4, 595-602 (2019).

65 Shi, T. \& Falkowski, P. G. Genome evolution in cyanobacteria: The stable core and the variable shell. Proc Natl Acad Sci U S A 105, 2510-2515 (2008).

66 Shih, P. M. et al. Improving the coverage of the cyanobacterial phylum using diversity-driven genome sequencing. Proc Natl Acad Sci U S A 110, 1053-1058 (2013).

67 Martins, M. C. et al. How superoxide reductases and flavodiiron proteins combat oxidative stress in anaerobes. Free Radic Biol Med 140, 36-60 (2019).

68 Slesak, I., Kula, M., Slesak, H., Miszalski, Z. \& Strzalka, K. How to define obligatory anaerobiosis? An evolutionary view on the antioxidant response system and the early stages of the evolution of life on Earth. Free Radic Biol Med 140, 61-73 (2019).

69 Fischer, W. W., Hemp, J. \& Valentine, J. S. How did life survive Earth's great oxygenation? Curr Opin Chem Biol 31, 166-178 (2016).

70 Neubeck, A. \& Freund, F. Sulfur Chemistry May Have Paved the Way for Evolution of Antioxidants. Astrobiology (2019).

71 Berghuis, B. A. et al. Hydrogenotrophic methanogenesis in archaeal phylum Verstraetearchaeota reveals the shared ancestry of all methanogens. Proc Natl Acad Sci U S A 116, 5037-5044 (2019).

72 Borrel, G. et al. Wide diversity of methane and short-chain alkane metabolisms in uncultured archaea. Nat Microbiol 4, 603-613 (2019).

73 Evans, P. N. et al. An evolving view of methane metabolism in the Archaea. Nature Reviews Microbiology 17, :219-232 (2019).

74 McKay, L. J. et al. Co-occurring genomic capacity for anaerobic methane and dissimilatory sulfur metabolisms discovered in the Korarchaeota. Nat Microbiol 4, 614-622 (2019).

75 Pittis, A. A. \& Gabaldon, T. Late acquisition of mitochondria by a host with chimaeric prokaryotic ancestry. Nature 531, 101-104 (2016).

76 Canfield, D. E. \& Des Marais, D. J. Aerobic sulfate reduction in microbial mats. Science 251, 14711473 (1991). 
641

642

643

644

645

646

647

648

649

650

651

652

653

654

655

656

657

658

659

660

661

662

663

664

665

666

667

668

669

670

671

672

673

674

675

676

677

678

679

680

681

682

683

684

685

686

687

688
77 Visscher, P. T. et al. Formation of lithified micritic laminae in modern marine stromatolites (Bahamas): The role of sulfur cycling. Am Mineral 83, 1482-1493 (1998).

78 Munoz-Gomez, S. A., Wideman, J. G., Roger, A. J. \& Slamovits, C. H. The Origin of Mitochondrial Cristae from Alphaproteobacteria. Molecular biology and evolution 34, 943-956 (2017).

79 Cavalier-Smith, T. Predation and eukaryote cell origins: a coevolutionary perspective. Int J Biochem Cell Biol 41, 307-322 (2009).

80 Martin, W. F., Garg, S. \& Zimorski, V. Endosymbiotic theories for eukaryote origin. Philos Trans R Soc Lond B Biol Sci 370, 20140330 (2015).

81 Martijn, J. \& Ettema, T. J. From archaeon to eukaryote: the evolutionary dark ages of the eukaryotic cell. Biochem Soc Trans 41, 451-457 (2013).

82 von Dohlen, C. D., Kohler, S., Alsop, S. T. \& McManus, W. R. Mealybug beta-proteobacterial endosymbionts contain gamma-proteobacterial symbionts. Nature 412, 433-436 (2001).

83 Sassera, D. et al. 'Candidatus Midichloria mitochondrii', an endosymbiont of the tick Ixodes ricinus with a unique intramitochondrial lifestyle. Int J Syst Evol Microbiol 56, 2535-2540 (2006).

84 Wujek, D. E. Intracellular bacteria in the blue-green alga Pleurocapsa minor Trans Am Microscop Soc 98, 143-145 (1979).

85 Larkin, J. M., Henk, M. C. \& Burton, S. D. Occurrence of a Thiothrix sp. attached to mayfly larvae and presence of parasitic bacteria in the Thiothrix sp. Appl Environ Microbiol 56, 357-361 (1990).

86 Larkin, J. M. \& Henk, M. C. Filamentous sulfide-oxidizing bacteria at hydrocarbon seeps of the gulf of Mexico. Microsc Res Tech 33, 23-31 (1996).

87 Yamaguchi, M. et al. Prokaryote or eukaryote? A unique microorganism from the deep sea. Microscopy 61, 423-431 (2012).

88 Shiratori, T., Suzuki, S., Kakizawa, Y. \& Ishida, K.-I. Phagocytosis-like cell engulfment by a planctomycete bacterium. Nat Commun 10, 5529-5529 (2019).

89 Heimerl, T. et al. A Complex Endomembrane System in the Archaeon Ignicoccus hospitalis Tapped by Nanoarchaeum equitans. Frontiers in microbiology 8 (2017).

90 Lombard, J., López-García, P. \& Moreira, D. The early evolution of lipid membranes and the three domains of life. Nat Rev Microbiol 10, 507-515 (2012).

91 Jekely, G. Origin and evolution of the self-organizing cytoskeleton in the network of eukaryotic organelles. Cold Spring Harb Perspect Biol 6, a016030 (2014).

92 Dacks, J. B. \& Field, M. C. Evolutionary origins and specialisation of membrane transport. Curr Opin Cell Biol 53, 70-76 (2018).

93 Dey, G., Thattai, M. \& Baum, B. On the archaeal origins of eukaryotes and the challenges of inferring phenotype from genotype. Trends in Cell Biology 26, 476-485 (2016).

94 Rout, M. P. \& Field, M. C. The Evolution of Organellar Coat Complexes and Organization of the Eukaryotic Cell. Annu Rev Biochem 86, 637-657 (2017).

95 Yutin, N., Wolf, M. Y., Wolf, Y. I. \& Koonin, E. V. The origins of phagocytosis and eukaryogenesis. Biol Direct 4, 9 (2009).

96 Lombard, J. The multiple evolutionary origins of the eukaryotic N-glycosylation pathway. Biology Direct 11 (2016).

97 Tromer, E. C., van Hooff, J. J. E., Kops, G. \& Snel, B. Mosaic origin of the eukaryotic kinetochore. Proc Natl Acad Sci U S A 116, 12873-12882 (2019).

98 Akıl, C. \& Robinson, R. C. Genomes of Asgard archaea encode profilins that regulate actin. Nature 562, 439-443 (2018).

99 Klinger, C. M., Spang, A., Dacks, J. B. \& Ettema, T. J. Tracing the archaeal origins of eukaryotic membrane-trafficking system building blocks. Molecular biology and evolution 33, 1528-1541 (2016).

100 Jekely, G. Small GTPases and the evolution of the eukaryotic cell. Bioessays 25, 1129-1138. (2003).

101 Low, H. H. \& Lowe, J. A bacterial dynamin-like protein. Nature 444, 766-769 (2006). 
701

702

703

704

705

706

707

708

709

710

711

712

713

714

715

716

717

718

719

720

721

722

723

724

725

726

727

728

729

730

731

732

733

734

735
102 Santana-Molina, C., Rivas-Marin, E., Rojas, A. M. \& Devos, D. P. Origin and evolution of polycyclic triterpene synthesis. Molecular biology and evolution, pii: msaa054. doi: 010.1093/molbev/msaa1054. [Epub ahead of print] (2020).

103 Caforio, A. et al. Converting Escherichia coli into an archaebacterium with a hybrid heterochiral membrane. Proc Natl Acad Sci U S A 115, 3704-3709 (2018).

104 Pogozheva, I. D., Tristram-Nagle, S., Mosberg, H. I. \& Lomize, A. L. Structural adaptations of proteins to different biological membranes. Biochim Biophys Acta 1828, 2592-2608 (2013).

105 Makarova, M. et al. Delineating the rules for structural adaptation of membrane-associated proteins to evolutionary changes in membrane lipidome. bioRxiv, 762146 (2019).

106 Shimada, H. \& Yamagishi, A. Stability of heterochiral hybrid membrane made of bacterial sn-G3P lipids and archaeal sn-G1P lipids. Biochem 50, 4114-4120 (2011).

107 Diekmann, Y. \& Pereira-Leal, J. B. Evolution of intracellular compartmentalization. Biochem J 449, 319-331 (2013).

108 Greene, S. E. \& Komeili, A. Biogenesis and subcellular organization of the magnetosome organelles of magnetotactic bacteria. Curr Opin Cell Biol 24, 490-495 (2012).

109 van Niftrik, L. A. et al. The anammoxosome: an intracytoplasmic compartment in anammox bacteria. FEMS Microbiol Lett 233, 7-13 (2004).

110 Jahn, M. T. et al. Shedding light on cell compartmentation in the candidate phylum Poribacteria by high resolution visualisation and transcriptional profiling. Sci Rep 6, 35860 (2016).

111 Fuerst, J. A. Intracellular compartmentation in Planctomycetes. Annu Rev Microbiol, 299-328 (2005).

112 Katayama, T. et al. Membrane-bounded nucleoid discovered in a cultivated bacterium of the candidate phylum 'Atribacteria'. bioRxiv, 728279 (2019).

113 Borgnia, M. J., Subramaniam, S. \& Milne, J. L. Three-dimensional imaging of the highly bent architecture of Bdellovibrio bacteriovorus by using cryo-electron tomography. J Bacteriol 190, 25882596 (2008).

114 Remis, J. P. et al. Bacterial social networks: structure and composition of Myxococcus xanthus outer membrane vesicle chains. Environ Microbiol 16, 598-610 (2014).

115 Naor, A., Lapierre, P., Mevarech, M., Papke, R. T. \& Gophna, U. Low species barriers in halophilic archaea and the formation of recombinant hybrids. Curr Biol 22, 1444-1448 (2012).

116 Nudleman, E., Wall, D. \& Kaiser, D. Cell-to-cell transfer of bacterial outer membrane lipoproteins. Science 309, 125-127 (2005).

117 Cao, P. \& Wall, D. Direct visualization of a molecular handshake that governs kin recognition and tissue formation in myxobacteria. Nat Commun 10, 3073 (2019).

118 Jakobczak, B., Keilberg, D., Wuichet, K. \& Sogaard-Andersen, L. Contact- and protein transferdependent stimulation of assembly of the gliding motility machinery in Myxococcus xanthus. PLoS Genet 11, e1005341 (2015).

119 Wolgemuth, C. W. \& Oster, G. The junctional pore complex and the propulsion of bacterial cells. J Mol Microbiol Biotechnol 7, 72-77 (2004).

120 Nan, B. \& Zusman, D. R. Uncovering the mystery of gliding motility in the myxobacteria. Annu Rev Genet 45, 21-39 (2011).

121 Munoz-Dorado, J., Marcos-Torres, F. J., Garcia-Bravo, E., Moraleda-Munoz, A. \& Perez, J. Myxobacteria: Moving, Killing, Feeding, and Surviving Together. Frontiers in microbiology 7, 781 (2016).

122 Patron, N. J. \& Waller, R. F. Transit peptide diversity and divergence: A global analysis of plastid targeting signals. Bioessays 29, 1048-1058 (2007).

123 Rogozin, I. B., Carmel, L., Csuros, M. \& Koonin, E. V. Origin and evolution of spliceosomal introns. Biol Direct 7, 11 (2012). 
124 Catania, F., Gao, X. \& Scofield, D. G. Endogenous mechanisms for the origins of spliceosomal introns. J Hered (2009).

125 Vosseberg, J. \& Snel, B. Domestication of self-splicing introns during eukaryogenesis: the rise of the complex spliceosomal machinery. Biol Direct 12, 30 (2017).

126 Martin, W. \& Koonin, E. V. Introns and the origin of nucleus-cytosol compartmentalization. Nature 440, 41-45 (2006).

127 D'Angelo, M. A. Nuclear pore complexes as hubs for gene regulation. Nucleus 9, 142-148 (2018).

128 Peña, C., Hurt, E. \& Panse, V. G. Eukaryotic ribosome assembly, transport and quality control. Nature Structural \&Amp; Molecular Biology 24, 689 (2017).

129 Feng, J. M., Tian, H. F. \& Wen, J. F. Origin and evolution of the eukaryotic SSU processome revealed by a comprehensive genomic analysis and implications for the origin of the nucleolus. Genome Biol Evol 5, 2255-2267 (2013).

130 Rivera, M. C., Jain, R., Moore, J. E. \& Lake, J. A. Genomic evidence for two functionally distinct gene classes. Proc. Natl. Acad. Sci. USA 95, 6239-6244 (1998).

131 Pisani, D., Cotton, J. A. \& Mclnerney, J. O. Supertrees disentangle the chimerical origin of eukaryotic genomes. Molecular biology and evolution 24, 1752-1760 (2007).

132 Gabaldon, T. \& Huynen, M. A. From endosymbiont to host-controlled organelle: the hijacking of mitochondrial protein synthesis and metabolism. PLoS Comput Biol 3, e219 (2007).

133 Gabaldon, T. Relative timing of mitochondrial endosymbiosis and the "pre-mitochondrial symbioses" hypothesis. IUBMB Life 70, 1188-1196 (2018).

$134 \mathrm{Ku}, \mathrm{C}$. et al. Endosymbiotic gene transfer from prokaryotic pangenomes: Inherited chimerism in eukaryotes. Proc Natl Acad Sci U S A 112, 10139-10146 (2015).

135 López-García, P., Zivanovic, Y., Deschamps, P. \& Moreira, D. Bacterial gene import and mesophilic adaptation in archaea. Nat Rev Microbiol 13, 447-456 (2015).

136 Larkum, A. W., Lockhart, P. J. \& Howe, C. J. Shopping for plastids. Trends Plant Sci 12, 189-195 (2007).

137 Philippe, H. et al. Comparison of molecular and paleontological data in diatoms suggests a major gap in the fossil record. J Evol Biol 7, 247-265 (1994).

138 Zhu, S. Evidence for myxobacterial origin of eukaryotic defensins. Immunogenetics 59, 949-954 (2007).

139 Perez, J., Castaneda-Garcia, A., Jenke-Kodama, H., Muller, R. \& Munoz-Dorado, J. Eukaryotic-like protein kinases in the prokaryotes and the myxobacterial kinome. Proc Natl Acad Sci U S A 105, 15950-15955 (2008).

140 Kerk, D., Uhrig, R. G. \& Moorhead, G. B. Bacterial-like PPP protein phosphatases: novel sequence alterations in pathogenic eukaryotes and peculiar features of bacterial sequence similarity. Plant Signal Behav 8, e27365 (2013).

141 Elias-Arnanz, M., Padmanabhan, S. \& Murillo, F. J. The regulatory action of the myxobacterial CarD/CarG complex: a bacterial enhanceosome? FEMS Microbiol Rev 34, 764-778 (2010).

142 Bock, T., Kasten, J., Muller, R. \& Blankenfeldt, W. Crystal Structure of the HMG-CoA Synthase MvaS from the Gram-Negative Bacterium Myxococcus xanthus. Chembiochem 17, 1257-1262 (2016).

143 Osborn, A. R. et al. Evolution and Distribution of C7-Cyclitol Synthases in Prokaryotes and Eukaryotes. ACS Chem Biol 12, 979-988 (2017).

144 Pereto, J., Lopez-Garcia, P. \& Moreira, D. Phylogenetic analysis of eukaryotic thiolases suggests multiple proteobacterial origins. J Mol Evol 61, 65-74 (2005).

145 Schluter, A., Ruiz-Trillo, I. \& Pujol, A. Phylogenomic evidence for a myxococcal contribution to the mitochondrial fatty acid beta-oxidation. PloS one 6, e21989 (2011).

146 Stairs, C. W., Leger, M. M. \& Roger, A. J. Diversity and origins of anaerobic metabolism in mitochondria and related organelles. Philos Trans R Soc Lond B Biol Sci 370, 20140326 (2015).

147 Baum, D. A. \& Baum, B. An inside-out origin for the eukaryotic cell. BMC Biol 12, 76 (2014). 
801

\section{Author contributions}

803 P.L.-G. and D.M. conceived and discussed the ideas presented in the manuscript. P.L.-G. wrote the 804 manuscript with critical input from D.M.

805

\section{Competing interests}

807 The author declares no competing financial interests.

149 Searcy, D. G. in The origin and evolution of the cell (eds H. Hartman \& K. Matsuno) 47-78 (World Scientific, 1992).

150 Searcy, D. G. Metabolic integration during the evolutionary origin of mitochondria. Cell Res 13, 229238 (2003).

151 Gould, S. B., Garg, S. G. \& Martin, W. F. Bacterial vesicle secretion and the evolutionary origin of the eukaryotic endomembrane system. Trends Microbiol 24, 525-534 (2016).

152 Embley, T. M. \& Martin, W. Eukaryotic evolution, changes and challenges. Nature 440, 623-630 (2006).

153 Field, M. C. \& Rout, M. P. Pore timing: the evolutionary origins of the nucleus and nuclear pore complex. F1000Res 8 (2019).

\section{Acknowledgements}

The authors acknowledge funding from the European Research Council (ERC) grants ProtistWorld (P.L.-G., Agreement No. 322669) and Plast-Evol (D.M., Agreement No. 787904), and the French Agence Nationale de la Recherche (P.L.-G., ANR-18-CE02-0013-1).
808

809

810

811

.




\section{Figure Legend}

813 Figure $1 \mid$ Environmental context, metabolic interactions and (endo)membrane evolution during 814 eukaryogenesis according to the HS-Syntrophy hypothesis. a, eukaryogenesis took place in phototrophic 815 microbial mats where steep redox gradients occur. Syntrophic interactions based on interspecies 816 hydrogen and/or sulfur transfer are widespread depending on local physicochemistry; they notably

817 involve methanogens, Asgard archaea, sulfate-reducing bacteria (SRB) and sulfide-oxidizing bacteria 818 (SOB). b-f, different eukaryogenesis steps. b, initial facultative symbiosis stage involving a hydrogen819 producing Asgard archaeon, a sulfate-reducing deltaproteobacterium and a sulfide-oxidizing 820 alphaproteobacterium possibly able to carry out oxygenic photosynthesis. c, first integration of the 821 Asgard archaeon as an endosymbiont (future nucleus). d, second integration step involving the 822 endosymbiosis of the alphaproteobacterium. Stages $\mathrm{c}$ and $\mathrm{d}$ might have been coetaneous (first eukaryotic 823 common ancestor - FECA - stage) or, more likely, decoupled in time (FECA 1 and 2). e, advanced 824 integration stage involving important changes in metabolism (the consortium relies on aerobic 825 respiration, all other previous metabolic interactions between partners being lost) and endomembrane 826 evolution. $\mathrm{f}$, last eukaryotic common ancestor stage (LECA). The position of $\mathrm{H}_{2}$ or any other substrate by 827 an arrow (over or under) implies transfer in the sense of the arrow; when it is on two arrows of opposed 828 directionality, transfer may occur either way. HGT, horizontal gene transfer; EGT, endosymbiotic gene 829 transfer; aa, amino acids; ER, endoplasmic reticulum; conc., concentration; Ox., oxygenic; Anox., 830 anoxygenic; SRB, sulfate-reducing bacteria; SOB, sulfide-oxidizing bacteria; FECA, first eukaryotic common 831 ancestor; LECA, last eukaryotic common ancestor; hv, photon-derived energy.

832 
Box 1 | Symbiogenetic models for the origin of eukaryotes based on metabolic exchange. established between archaeal and bacterial cells in anoxic or microoxic environments. Most of them involve only two partners, one archaeon and the alphaproteobacterial ancestor of mitochondria. However, some models invoke the participation of one additional bacterium, either transiently, as facilitator of the eukaryogenetic symbiosis ${ }^{18}$, or as an integral part of $\mathrm{it}^{19,26}$. One of the oldest proposals based on explicit syntrophy was that of D. Searcy, who stated that eukaryotes derived from a sulfurmediated symbiosis between a wall-less, sulfur-respiring Thermoplasma-like archaeon and photo- or chemoautotrophic $\mathrm{H}_{2} \mathrm{~S}$-utilizing bacterium ${ }^{149,150}$. The original Hydrogen hypothesis postulated a hydrogenmediated symbiosis between a hydrogenoclastic methanogenic archaeon and a hydrogen-producing alphaproteobacterium, hydrogen being used to reduce the $\mathrm{CO}_{2}$ also released by the bacterium for methanogenesis ${ }^{25}$. In a more recent version of the Hydrogen hypothesis, the initial methanogenic host was abandoned in favor of an autotrophic, non-methanogenic, archaeon that would use the WoodLjungdahl pathway to fix carbon using the hydrogen released by the mitochondrial ancestor ${ }^{148}$. Based on the inferred ancestral metabolism of Asgard archaea, which likely were organoheterotrophs with flexible potential for hydrogen consumption and production, Spang and co-workers put forward the Reverse Flow model. In this model, the eukaryogenetic syntrophy was based on hydrogen transfer (or electrons, i.e. reducing equivalents, which might be also mediated by formate or acetate) from the anaerobic heterotrophic archaeon to the alphaproteobacterium ${ }^{16}$. The recent Entangle-Engulf-Enslave $-\mathrm{E}^{3}$ model $^{18}$ favors a dual symbiosis of an Asgard archaeon that degraded amino acids to short-chain fatty acids and hydrogen with a sulfate-reducing bacterium (SRB) and an aerobic organotrophic alphaproteobacterium in microoxic environments that scavenged toxic $\mathrm{O}_{2}$. As the consortium progresses towards increasingly oxic zones, the interaction with the alphaproteobacterium becomes stronger until it is engulfed. The SRB symbiosis is transient and eventually lost ${ }^{18}$. Finally, the original version of the Syntrophy hypothesis (HMSyntrophy) postulated a tripartite integrative symbiosis. First, a syntrophy based on interspecies $\mathrm{H}_{2}$ -

858 transfer was established between a fermentative, ancestrally sulfate-reducing, myxobacterium 859 (Deltaproteobacteria) and a methanogenic archaeon using the fermentation-derived hydrogen for methanogenesis. Subsequently, a metabolically versatile alphaproteobacterium able to carry out facultative aerobic respiration but also to oxidize methane (methanotroph) incorporated stably into the consortium $^{19,26}$. In the revised variant of the Syntrophy model (HS-Syntrophy model), we hypothesize a 863 symbiosis between a hydrogen-releasing Asgard archaeon able to degrade small organics and a complex, 864 myxobacterial-like, deltaproteobacterial host scavenging hydrogen (reducing equivalents) for sulfate 865 reduction. The alphaproteobacterial ancestor of mitochondria was a sulfide-oxidizing facultative aerobe, 866 recycling sulfur in the consortium. Possibly, it was also a mixotrophic organism able to carry out 867 anoxygenic photosynthesis using $\mathrm{H}_{2} \mathrm{~S}$ as electron donor. 
Box 2 | Symbiogenetic models for the origin of eukaryotes according to the timing and mode of evolution of 873 key eukaryotic traits.

874 Regardless the metabolic basis of the symbiosis established between the Asgard archaeon and its 875 bacterial partner(s) during eukaryogenesis, models differ in the proposed mechanisms that resulted in the physical integration of two or more cells in one (future eukaryotic cell) and the evolution of typical eukaryotic traits as well as in the relative timing of the involved events (a-e). The Syntrophy hypothesis is the only model where a membrane transition is not needed, since the host (future cytoplasm) is a deltaproteobacterium naturally endowed with bacterial phospholipids (a). The future nucleus has an early origin in this model; it would derive from a distinct metabolic compartment (endosymbiotic archaeon) that is progressively confined by a host-derived secretory membrane (Med., medium). Mitochondria appear relatively late. In the Hydrogen hypothesis ${ }^{25}$, the endosymbiosis of the alphaproteobacterial ancestor of mitochondria within an archaeon by means independent of classical, eukaryotic-like phagocytosis (Ek-phagocytosis* in the figure) is the starting event triggering eukaryogenesis (b). The nucleus and the associated membrane system would form de novo from lipid vesicles produced by the alphaproteobacterium ${ }^{126,151}$. The archaeal membrane phospholipids would have been fully replaced by the bacterial phospholipids by the fusion of those bacterial vesicles with the outer plasma membrane and the progressive displacement of archaeal lipids ${ }^{151}$. In the currently most widely accepted type of eukaryogenetic models, which include the 'phagocytosing archaeon's1 hypothesis (c) and the 'reverse flow' model (d), the development of a complex cytoskeleton and endomembrane system predate the acquisition of the mitochondrial ancestor by classical phagocytosis ${ }^{6,9,16}$. Although these two models show similarities, in the 'phagocytosing archaeon' model the nucleus would appear before the mitochondrial acquisition, in contrast with the 'reverse flow' model. At any rate, in these models (c, d) the mitochondrial endosymbiosis would be the consequence of an already well engaged eukaryogenetic process. From this perspective, these models represent the transposition of past scenarios based on the existence of a proto-eukaryotic lineage different from archaea and bacteria endowed with all typical eukaryotic traits but mitochondria, ${ }^{4,5,79,152}$ to a nucleus-lacking proto-eukaryotic Asgard archaeon that is already seen as the first eukaryotic common ancestor (FECA $)^{6,153}$. These two models and the hydrogen hypothesis clearly differ in the timing of the mitochondrial acquisition and the endomembrane system but, in the three cases, the archaeal membrane phospholipids are replaced relatively late by bacterialtype phospholipids (b-d). In another set of models, including the inside-out ${ }^{147}$ and the $\mathrm{E}^{3}$ hypotheses, the mitochondrial ancestor is acquired relatively late by a slow process of engulfment. This involves archaeal membrane extrusions that progressively surround, entangle and end up by enslaving the future mitochondria (e). At least in the inside-out model, the archaeal-to-bacterial membrane phospholipid transition would occur relatively early, facilitated by close cell-cell contact and symbiotic gene transfer. According to this model, only bacterial membranes, much more flexible than the archaeal ones, would be able to form an endomembrane system and carry out phagocytosis ${ }^{147}$. Finally, in the Serial Endosymbiosis model, several sequential symbioses intervene ${ }^{75,133}$. Although the details remain undetermined, the mitochondrion would be acquired late (f).

910

911

912

913 insert Fig. Box 2 here 


\begin{tabular}{|c|c|c|}
\hline & Test - Means of obtaining answers & Models favored or disfavored \\
\hline \multicolumn{3}{|l|}{ Predictions of the HS-syntrophy hypothesis } \\
\hline $\begin{array}{l}\text { Existence of a versatile SRB deltaproteobacterial } \\
\text { lineage, possibly sharing complex traits in common } \\
\text { with myxobacteria, closer to eukaryotes }\end{array}$ & $\begin{array}{l}\text { Explore microbial ecosystems relevant for eukaryogenesis } \\
\text { (sediments, microbial mats) in search for novel } \\
\text { deltaproteobacterial lineages followed by phylogenomic } \\
\text { analyses }\end{array}$ & $\begin{array}{l}\text { The detection of deltaproteobacterial lineages sharing a common } \\
\text { and stronger phylogenetic signal with eukaryotes as compared to } \\
\text { other bacteria would be consistent with the HS-Syntrophy model }\end{array}$ \\
\hline $\begin{array}{l}\text { Existence of an alphaproteobacterial lineage of } \\
\text { versatile S-oxidizers, perhaps photosynthetic, closer } \\
\text { to mitochondria }\end{array}$ & $\begin{array}{l}\text { Explore microbial ecosystems relevant for eukaryogenesis } \\
\text { in search for novel alphaproteobacterial lineages followed } \\
\text { by phylogenomic analyses }\end{array}$ & $\begin{array}{l}\text { The detection of sulfide-oxidizing, potentially photosynthetic, } \\
\text { alphaproteobacterial lineages sharing a common phylogenetic } \\
\text { signal with eukaryotes to the exxclusion of other bacteria would } \\
\text { be consistent with the HS-Syntrophy model }\end{array}$ \\
\hline $\begin{array}{l}\text { A large fraction of bacterial genes in eukaryotes } \\
\text { predates the mitochondrial endosymbiosis and } \\
\text { derives from Deltaproteobacteria }\end{array}$ & $\begin{array}{l}\text { Improve phylogenetic analyses of bacterial genes across } \\
\text { eukaryotes, particularly those present in LECA }\end{array}$ & $\begin{array}{l}\text { The presence, function and relative amount of } \\
\text { deltaproteobacterial-like genes in eukaryotes as compared to } \\
\text { other bacterial-like genes might support the involvement of a } \\
\text { deltaproteobacterial symbiont in eukaryogenesis }\end{array}$ \\
\hline $\begin{array}{l}\text { Deltaproteobacterial genes mostly relate to } \\
\text { membrane, cell signaling and cytoplasm functions }\end{array}$ & $\begin{array}{l}\text { Improve phylogenetic analyses and functional annotation } \\
\text { of deltaproteobacterial-like genes in eukaryotes }\end{array}$ & $\begin{array}{l}\text { The involvement of deltaproteobacterial genes in membrane, cell } \\
\text { signaling and cytoplasmic functions would be supportive of the HS- } \\
\text { Syntrophy model }\end{array}$ \\
\hline $\begin{array}{l}\text { Bacterial genes widespread in eukaryotes (present } \\
\text { in LECA) largely derive from EGT, not HGT }\end{array}$ & $\begin{array}{l}\text { Improve phylogenetic analyses of bacterial genes present } \\
\text { in LECA and look for potential homologues in Asgard } \\
\text { archaea and in the closest alphaproteobacterial ancestors } \\
\text { of mitochondria }\end{array}$ & $\begin{array}{l}\text { If those bacterial-like genes in eukaryotes are missing in Asgard } \\
\text { archaea or in Alphaproteobacteria, or the potential homologues } \\
\text { are more distantly related than genes from other prokaryotic } \\
\text { lineages, models invoking bacterial symbioses prior to the } \\
\text { mitochondrial symbiosis would be favored }\end{array}$ \\
\hline \multicolumn{3}{|l|}{ More general questions / problems } \\
\hline \multicolumn{3}{|l|}{ Prokaryotic endosymbiosis and origin of nucleus } \\
\hline $\begin{array}{l}\text { Do endosymbiotic prokaryotes exist in free-living } \\
\text { prokaryotes? Do endosymbiotic archaea exist } \\
\text { within bacteria? }\end{array}$ & $\begin{array}{l}\text { Look for potential prokaryotic endosymbionts in } \\
\text { anoxic/redox-transition ecosystems such as sediments or } \\
\text { microbial mats. }\end{array}$ & $\begin{array}{l}\text { If prokaryotic endosymbionts occur within prokaryotes, models } \\
\text { proposing early prokaryotic endosymbionts would be as favored } \\
\text { as models for which eukaryotic-like phagocytosis is a prerequisite. } \\
\text { Finding archaeal endosymbionts within bacteria would relieve } \\
\text { constraints for models proposing the endosymbiosis of one } \\
\text { archaeon within a bacterium during eukaryogenesis }\end{array}$ \\
\hline \multicolumn{3}{|l|}{ Mitochondria: original metabolism and timing } \\
\hline $\begin{array}{l}\text { What was the metabolism of the } \\
\text { alphaproteobacterial mitochondrial ancestor like? } \\
\text { Did it have genes from other bacteria? }\end{array}$ & $\begin{array}{l}\text { Explore microbial ecosystems in search for novel } \\
\text { alphaproteobacterial lineages closely related to the } \\
\text { mitochondrial lineage }\end{array}$ & $\begin{array}{l}\text { If the closest alphaproteobacteria to the mitochondrion are } \\
\text { identified, they might provide clues about the metabolic } \\
\text { properties of the mitochondrial ancestor, potentially favoring } \\
\text { specific eukaryogenesis models. If non-alphaproteobacterial } \\
\text { genes in eukaryotes can be mapped back to these } \\
\text { alphaproteobacteria, the origin of those genes would be more } \\
\text { easily explained by HGT to the mitochondrial ancestor from other } \\
\text { bacteria }\end{array}$ \\
\hline $\begin{array}{l}\text { Will the inclusion of more bacterial and archaeal } \\
\text { genomes potentially more closely related to } \\
\text { eukaryotes lead to the discovery of genes displaying } \\
\text { similarly long branches in phylogenetic trees as } \\
\text { compared to alphaproteobacterial genes? }\end{array}$ & $\begin{array}{l}\text { Enrich the taxonomic sampling of Asgard archaea and } \\
\text { bacteria having close homologues in eukaryotic genomes }\end{array}$ & $\begin{array}{l}\text { The discovery of an Asgard and/or bacterial lineage closer to } \\
\text { eukaryotes and displaying branches of equivalent length to that of } \\
\text { alphaproteobacterial-like genes in eukaryotes in phylogenetic } \\
\text { trees might imply a simultaneous or temporally close symbiotic } \\
\text { interaction of archaea and/or other bacteria during } \\
\text { eukaryogenesis }\end{array}$ \\
\hline \multicolumn{3}{|l|}{ Origin and nature of eukaryotic membranes } \\
\hline $\begin{array}{l}\text { Can bacteria expressing archaeal phospholipids be } \\
\text { stably maintained? }\end{array}$ & $\begin{array}{l}\text { Carry out experiments progressively expressing more } \\
\text { archaeal phospholipids in bacteria until the complete } \\
\text { replacement of bacterial phospholipds (eventually } \\
\text { knocking out bacterial phospholipid synthesis genes) }\end{array}$ & $\begin{array}{l}\text { If bacteria bearing membranes where bacterial phospholipids } \\
\text { have been fully replaced by archaeal phospholipids can be } \\
\text { experimentally produced, a bacterial-to-archaeal membrane } \\
\text { transition would have been historically feasible }\end{array}$ \\
\hline If so, what is the fitness cost? & $\begin{array}{l}\text { Study fitness of bacteria with archaeal phospholipids in } \\
\text { their membrane in long-term experiments with and } \\
\text { without competition with wild/other strains and as a } \\
\text { function of environmental conditions }\end{array}$ & $\begin{array}{l}\text { If fitness decreases and if bacteria cannot compete under any } \\
\text { tested environmental conditions with wild strains and/or other } \\
\text { bacteria, a membrane transition would have been historically } \\
\text { unlikely }\end{array}$ \\
\hline Does the whole proteome evolve? & $\begin{array}{l}\text { Study how the proteome change in eperimental evolution } \\
\text { as a function of archaeal phospholipid content in bacterial } \\
\text { membranes }\end{array}$ & $\begin{array}{l}\text { If important changes in the proteome are observed, this imposes } \\
\text { constraints for models invoking a membrane-transition }\end{array}$ \\
\hline $\begin{array}{l}\text { Can we answer in the same way to the three } \\
\text { previous questions for archaea expressing bacterial } \\
\text { phospholipids? }\end{array}$ & $\begin{array}{l}\text { Engineer archaeal cells with bacterial phospholipids and } \\
\text { carry out similar experiments as described above for } \\
\text { bacteria expressing archaeal phospholipids }\end{array}$ & $\begin{array}{l}\text { If if archaea bearing membranes with only bacterial phospholipids } \\
\text { can be produced, an archaeal-to-bacterial type membrane } \\
\text { transition could have been historically feasible. If not, the fitness } \\
\text { is too high for archaea to compete with wild-type archaea and/or } \\
\text { in natural environments and the proteome is significantly } \\
\text { affected, an archaeal-to-bacterial type membrane transition } \\
\text { would have been historically unlikely }\end{array}$ \\
\hline
\end{tabular}

917 
Searcy's model
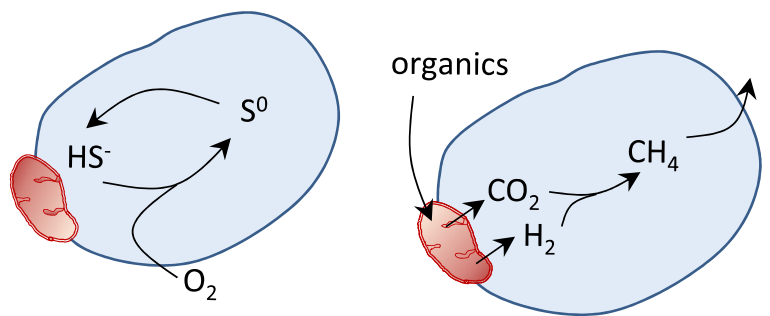

Updated Hydrogen hypothesis

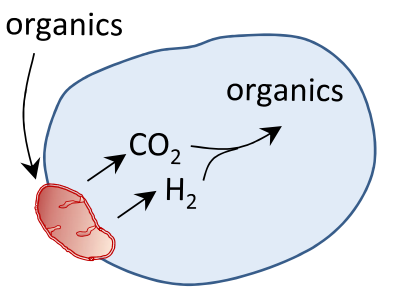

Reverse flow model

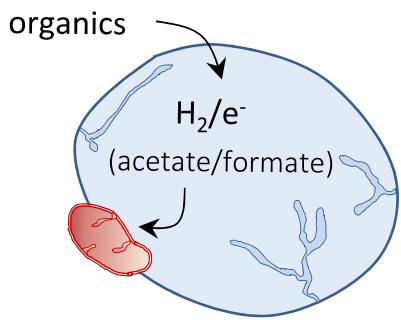

$E^{3}$ model

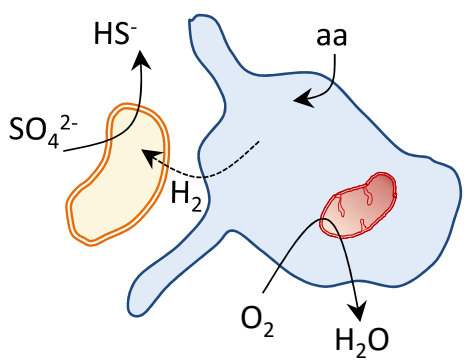

Archaeon
HM - Syntrophy hypothesis

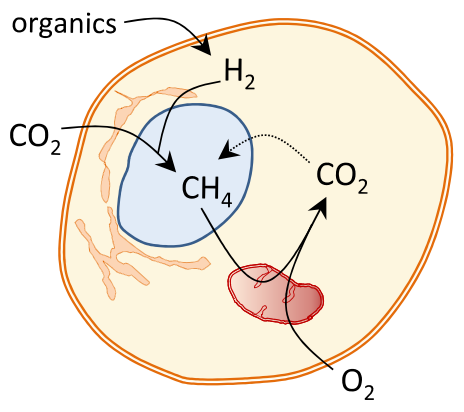

\section{HS - Syntrophy hypothesis}

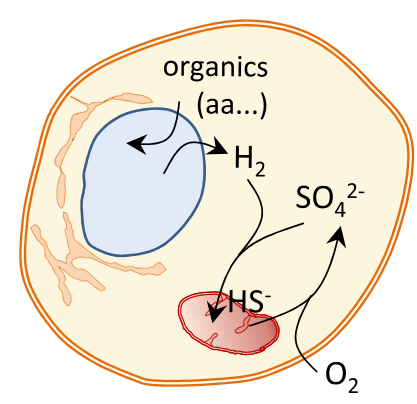

Figure Box 1. Lopez-Garcia \& Moreira (R2) 


\section{Tempo of key eukaryotic trait evolution}

a

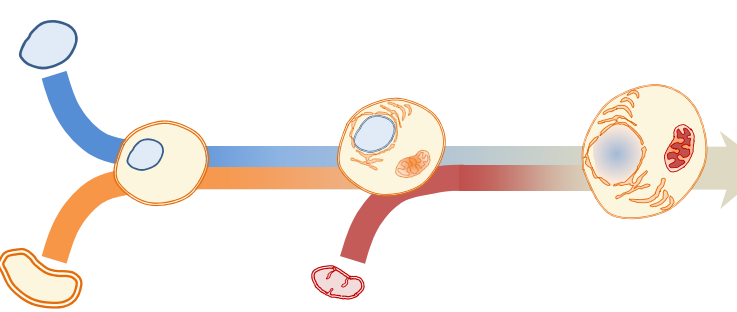

b

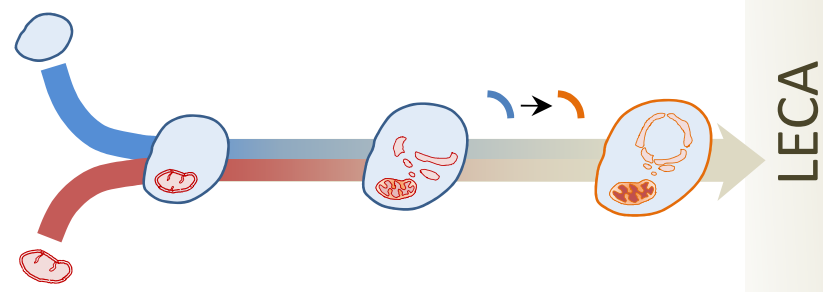

c

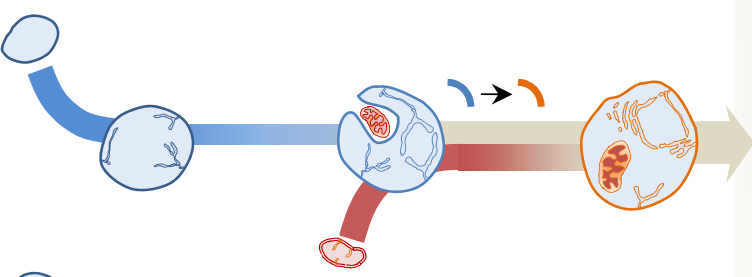

d 0

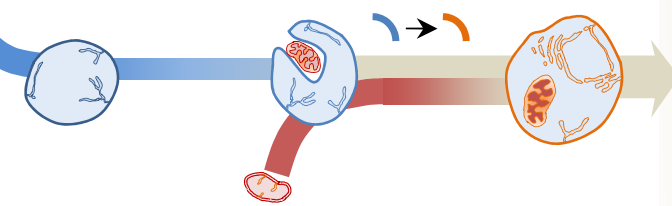

e $\xi$

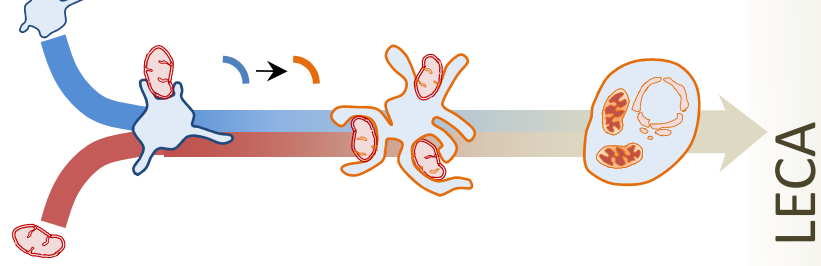

f

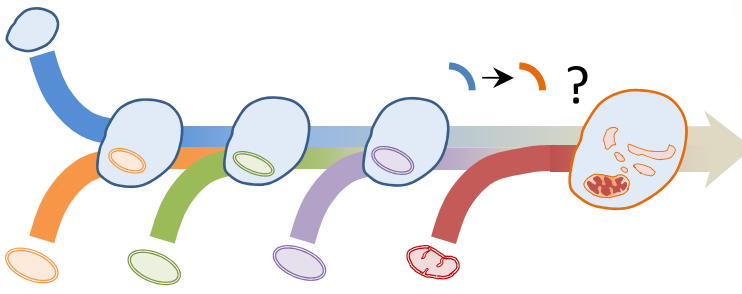

Undet. Undet. Late Undet. YES (undet.)
Models

Med. Late Late Early NO

Syntrophy

hypothesis

Late Late Early Late YES

Hydrogen

hypothesis

Early Med. Late Med. YES

Phagocytosing archaeon model

Early Med. Late Late YES

(late)

Reverse flow model

Late Late Late Early YES Inside-out model (early) E3 model

Serial endosymbiosis model 
a
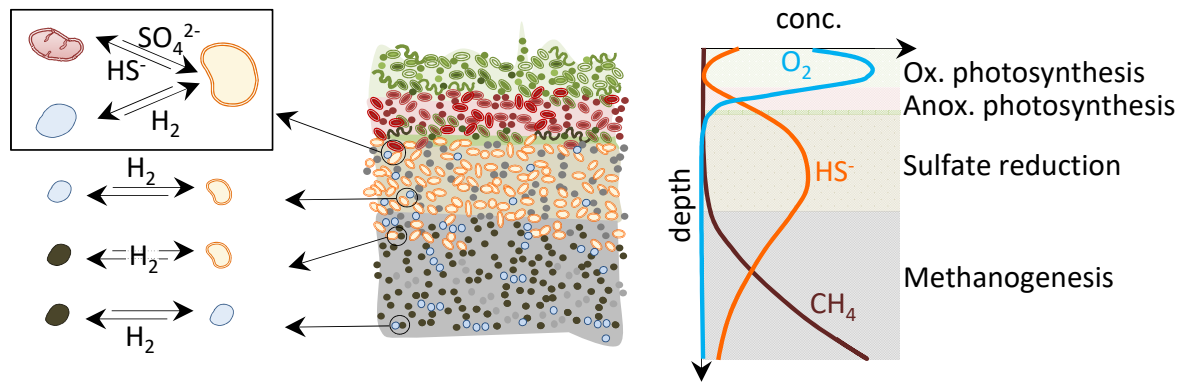

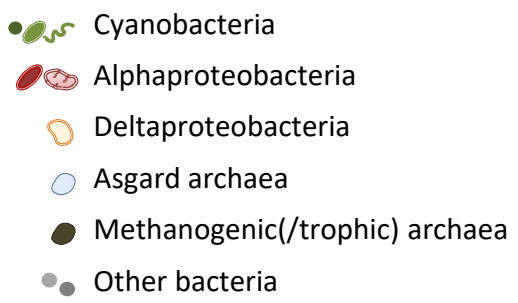

METABOLISM b

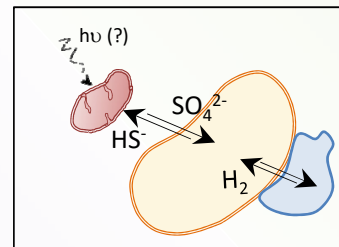

C Endosymbiosis is stablilized by HGT. HGT becomes EGT.

- The periplasmic space, where complex organics are hydrolyzed to simpler molecules, starts to develop in the vicinity of the archaeon to facilitate the transfer of amino acids and potentially other simple organics

d

- Extensive development of internal periplasmic membrane in contact with the archaeon (future nuclear membrane)

- The incipient endomembrane system has secretory purposes - direct export of hydrolytic enzymes to the periplasm without damaging the cytoplasm - as the archaeon enriches its genome and starts to centralize protein synthesis

e

- Transport channels traversing the archaeal membrane and the protonuclear membrane evolve to facilitate protein transport to the future eukaryotic cytoplasme via the endomembrane system

- Translation locates preferentially in close association with the membrane in proximity of membrane pores.

- Loss or archaeal membrane

- Ribosomes progressively migrate along the endomembrane system (future ER)

- Transcription (occurring in the archaeon - future nucleus) and translation (associated to the ER) become uncoupled

- Introns start invading the future eukaryotic genome. Rapid genome evolution and size increase.

- The periplasm becomes fully internalized keeping its original digestive (specialized vacuoles/organelles) and secretory (ER, exocytotic, endocytotic) functions

- The proto-nuclear membrane is retained to maintain transcription and translation uncoupled and prevent aberrant protein synthesis after intron invasion.

- The nuclear pore regulates traffic across compartments

- Ribosomal particles are still assembled in the nucleus

\section{MEMBRANES - NUCLEUS - GENOME}

- Obligatory symbiosis of one hydrogen-producing Asgard archaeon as endosymbiont in a complex sulfate-reducing deltaproteobacterium. Organics are degraded in the periplasm to simpler organics, then passed to the archaeon for further degradation accompanied with hydrogen production

- Facultative symbiosis of a metabolically versatile sulfide-oxidizing alphaproteobacterium, potentially photosynthetic/myxotrophic, with the sulfate-reducing consortium

- The symbiosis with the facultatively aerobic alphaproteobacterium becomes obligatory.

- Tripartite obligatory symbiotic stage

- The consortium increasingly relies on much more efficient aerobic respiration, especially in upper mat zones, and is able to colonize fully oxic environments

- Loss of bacterial sulfate-reduction

- Loss or archaeal energy metabolism

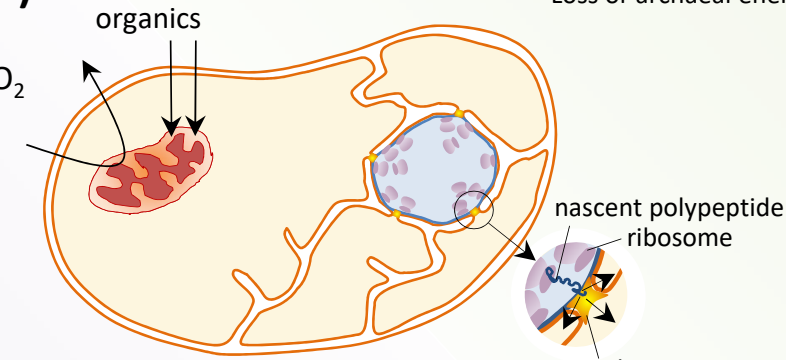

proto-nuclear pore

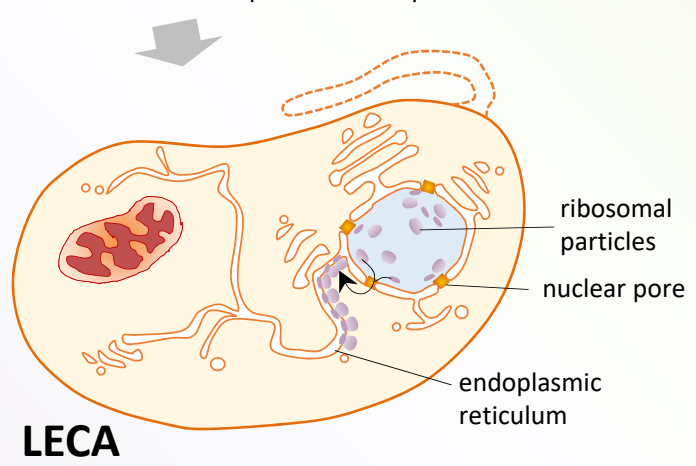

